\title{
Mitochondria and metabolic transitions in cardiomyocytes: lessons from development for stem cell-derived cardiomyocytes
}

\author{
Jessica C. Garbern ${ }^{1,2}$ and Richard T. Lee ${ }^{1,3^{*}}$
}

\begin{abstract}
Current methods to differentiate cardiomyocytes from human pluripotent stem cells (PSCs) inadequately recapitulate complete development and result in PSC-derived cardiomyocytes (PSC-CMs) with an immature or fetallike phenotype. Embryonic and fetal development are highly dynamic periods during which the developing embryo or fetus is exposed to changing nutrient, oxygen, and hormone levels until birth. It is becoming increasingly apparent that these metabolic changes initiate developmental processes to mature cardiomyocytes. Mitochondria are central to these changes, responding to these metabolic changes and transitioning from small, fragmented mitochondria to large organelles capable of producing enough ATP to support the contractile function of the heart. These changes in mitochondria may not simply be a response to cardiomyocyte maturation; the metabolic signals that occur throughout development may actually be central to the maturation process in cardiomyocytes. Here, we review methods to enhance maturation of PSC-CMs and highlight evidence from development indicating the key roles that mitochondria play during cardiomyocyte maturation. We evaluate metabolic transitions that occur during development and how these affect molecular nutrient sensors, discuss how regulation of nutrient sensing pathways affect mitochondrial dynamics and function, and explore how changes in mitochondrial function can affect metabolite production, the cell cycle, and epigenetics to influence maturation of cardiomyocytes.
\end{abstract}

Keywords: Stem cells, Cardiomyocytes, Mitochondria, Maturation, Metabolic regulation

\section{Introduction}

Human pluripotent stem cells (PSCs) are capable of efficiently differentiating into beating cardiomyocytes within less than 2 weeks [1]. However, these PSC-derived cardiomyocytes (PSC-CMs) are immature, with characteristics that more closely resemble fetal cardiomyocytes than mature, adult cardiomyocytes [2]. Numerous strategies have been proposed to enhance maturation of

\footnotetext{
* Correspondence: richard_lee@harvard.edu

'Department of Stem Cell and Regenerative Biology and the Harvard Stem Cell Institute, Harvard University, 7 Divinity Ave, Cambridge, MA 02138, USA ${ }^{3}$ Division of Cardiovascular Medicine, Department of Medicine, Brigham and Women's Hospital and Harvard Medical School, 75 Francis St, Boston, MA 02115, USA

Full list of author information is available at the end of the article
}

PSC-CMs including electrical stimulation, prolonged time in culture, or use of patterned substrates with some success [2]. New studies reveal that metabolic stimuli such as glucose removal, fatty acids, or hormones can improve PSC-CM maturation [3-7]. These interventions recapitulate aspects of metabolic transitions that occur during embryonic, fetal, and postnatal development $[8,9]$. In particular, birth itself triggers innumerable molecular changes as the body transitions from receiving all oxygen and nutrients from the placenta to breathing and eating independently. It is this window of time that cardiomyocytes transition from a proliferative state to a quiescent state $[10,11]$.

\section{$\triangle B M C$}

(c) The Author(s). 2021 Open Access This article is licensed under a Creative Commons Attribution 4.0 International License, which permits use, sharing, adaptation, distribution and reproduction in any medium or format, as long as you give appropriate credit to the original author(s) and the source, provide a link to the Creative Commons licence, and indicate if changes were made. The images or other third party material in this article are included in the article's Creative Commons licence, unless indicated otherwise in a credit line to the material. If material is not included in the article's Creative Commons licence and your intended use is not permitted by statutory regulation or exceeds the permitted use, you will need to obtain permission directly from the copyright holder. To view a copy of this licence, visit http://creativecommons.org/licenses/by/4.0/ The Creative Commons Public Domain Dedication waiver (http://creativecommons.org/publicdomain/zero/1.0/) applies to the data made available in this article, unless otherwise stated in a credit line to the data. 
Common molecular mechanisms triggered by metabolic shifts may contribute to both cardiomyocyte cell cycle exit and maturation. In particular, mitochondria are central to both sensing and regulating transitions in nutrient availability [12]. Mitochondria also undergo maturation during the perinatal window, transitioning from small, fragmented organelles to large networks with developed cristae capable of the high oxidative capacity needed to produce enough ATP to support the contractility required of the postnatal heart [12]. This maturation process of mitochondria is likely not merely a response to overall cardiomyocyte maturation; rather, mitochondria may be mediators of the molecular processes triggering maturation of cardiomyocytes. Thus, understanding how metabolic transitions during development might affect mitochondria and how mitochondria can affect cardiomyocyte maturation is important to develop strategies to improve and accelerate the maturation process. In this review, we discuss the role that normoxia, enteral feeding, and hormone changes during the perinatal window can affect mitochondria; next, we highlight features of mitochondria that can be regulated by nutrient sensors; finally, we review how changes in mitochondria can regulate cell cycle activity, metabolite formation, epigenetic behavior, and electrophysiological properties of cardiomyocytes.

\section{Features of immature and mature cardiomyocytes}

The features of immature, PSC-CMs compared to mature, adult cardiomyocytes have been reviewed extensively $[2,13,14]$. In brief, immature PSC-CMs have less organized and smaller sarcomeres $(\sim 1.65 \mu \mathrm{m})$, lower maximum contractile force, slower upstroke velocity, higher resting potential (around $-60 \mathrm{mV}$ ), absent $\mathrm{T}$ tubules, and continued reliance on glycolysis as the primary energy source [14]. In contrast, mature, adult cardiomyocytes have more organized and longer sarcomeres $(\sim 2.2 \mu \mathrm{m})$, exhibit a lower resting membrane potential (around $-90 \mathrm{mV}$ ), and rely on oxidative phosphorylation for ATP production [2]. Mitochondria of immature PSC-CMs are small and distributed throughout the cytoplasm including many located in the perinuclear space, while mature mitochondria are larger and primarily intermyofibrillar or subsarcolemmal [2]. Prolonging culture time of PSC-CMs can increase mitochondrial content yet mitochondrial function and cardiomyocyte phenotype remain immature [15]. This raises a question reminiscent of the chicken and the egg dilemma: which comes first-mitochondrial maturation or cardiomyocyte maturation? Although both processes are intertwined, we focus here on mitochondrial responses to metabolic stimuli and consider their potential role as drivers of cardiomyocyte maturation.

\section{Overview of molecular sensors and mitochondrial responses}

Molecular sensors detect changes in oxygen, energy, or nutrient levels to effect downstream transcriptional, translational, post-translational, or epigenetic modifications to enable responses to the environmental stimuli [16-19]. As one of the first organs to form during embryonic development, the heart must be able to utilize a variety of metabolic substrates in order to sustain its energy requirements throughout development. Cardiomyocytes retain this flexibility to utilize different substrates for ATP production, and shifts in the metabolic state can exert downstream effects that alter phenotype during development and disease states.

Major molecular metabolic/nutrient sensors in cardiomyocytes include hypoxia-inducible factors (HIFs; activated with low oxygen tension) [18], AMP-activated protein kinase (AMPK) (activated by low intracellular ATP levels in starvation conditions [20]), the mechanistic target of rapamycin (mTOR) (activated in nutrientrich conditions [21]), and fatty acid receptors (e.g., CD36) [16]. Each of these systems has a close relationship with mitochondria, on whom they depend to transmit their signals to downstream processes (Fig. 1). In response to signals from these sensors, mitochondria can respond by changing the balance of mitochondrial fission and fusion, undergoing mitochondrial biogenesis, and/or initiating mitophagy to remove dysfunctional mitochondria. These mitochondrial morphologic changes have effects downstream by changing the oxidative capacity, mitochondrial membrane potential, and reactive oxygen species (ROS) levels to control cardiomyocyte phenotype [22]. We will discuss each of these further in the context of the different metabolic transitions below but briefly review their role in mitochondrial dynamics and function here.

Oxygen levels regulate activity of the HIF family of transcription factors, which are degraded under normoxic conditions and stabilized under hypoxic conditions [18] or can be activated by mTOR signaling [23]. HIFs consist of an oxygen-sensitive $\alpha$ unit (HIF- $1 \alpha$ or HIF- $2 \alpha$ ) which dimerizes with HIF- $1 \beta$ to enact transcriptional changes aimed to promote cell survival in hypoxic conditions [24]. HIF- $1 \alpha / 2 \alpha$ suppresses oxidative phosphorylation by downregulating enzymes involved in the citric acid cycle to reduce acetyl-CoA formation and suppress electron transport chain activity in mitochondria, instead upregulating lactate dehydrogenase A (LDHA) to support glucose and lactate-mediated ATP production via glycolysis [24]. Interactions between HIFs and mitochondria have been reviewed previouslybriefly, HIFs can downregulate mitochondrial biogenesis via crosstalk with AMPK signaling, differentially alter mitochondrial fission and fusion with acute or chronic 


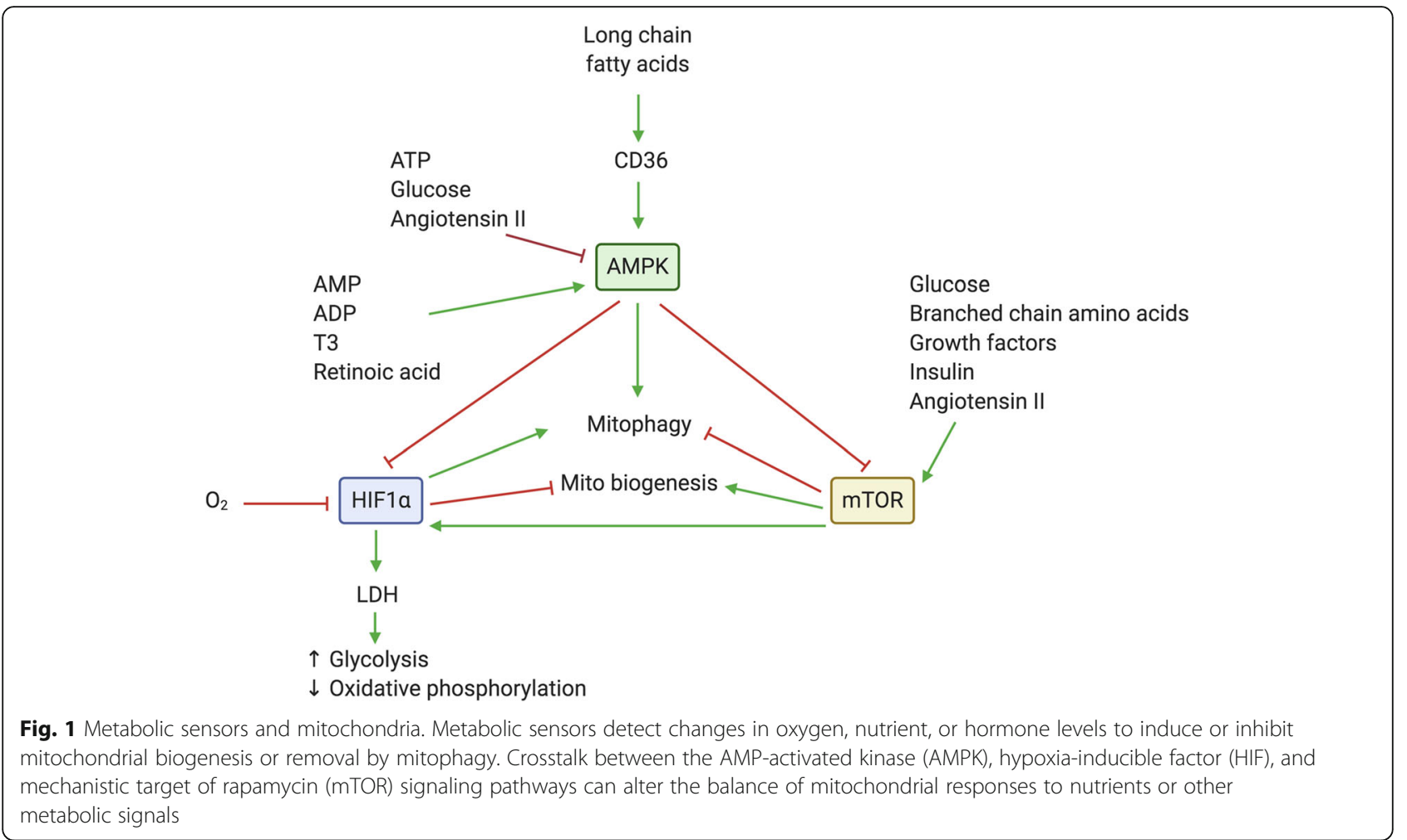

hypoxia, alter expression of microRNAs that regulate mitochondrial function, and can upregulate antioxidant defense systems to minimize damage from ROS [25].

Nutrient sensors respond to alterations in glucose, amino acid, or fatty acid levels. AMPK is activated by increased levels of AMP and ADP, and as an energy sensor, it detects low glucose levels and initiates catabolic pathways to maintain energy homeostasis [20]. AMPK stimulates mitochondrial biogenesis and activates mitochondrial turnover via mitophagy by activating Unc-51-like kinase 1 (ULK1) [20]. The mTOR kinase acts through mTOR complex 1 (mTORC1) to increase protein synthesis and fatty acid metabolism and decrease autophagy or mTOR complex 2 (mTORC2) to promote cell survival [26]. mTOR signaling can be activated by glucose as well as amino acids and growth factors such as insulin and is negatively regulated by AMPK [16]. The fatty acid transporter, CD36, senses long-chain fatty acids and can activate AMPK [27]. In addition, it can modulate intracellular calcium levels or associate with the outer mitochondria membrane to regulate oxidative phosphorylation [27]. It is evident that molecular crosstalk between these metabolic sensors finely tunes the phenotypic response of cardiomyocytes in response to different substrates.

\section{Major metabolic transitions from fetal to postnatal life}

Several excellent reviews have highlighted the many transitions that mammals undergo from embryonic formation to birth as they relate to cardiomyocyte maturation $[8,9,13,28]$. Here, we focus on how these transitions specifically affect molecular nutrient sensors and how these sensors regulate mitochondria (Fig. 1). We use examples from both stem cells and development to underscore how mitochondria are much more than simply energy-producing organelles, acting to both listen to metabolic signals and coordinate cellular changes in response.

\section{Spontaneous breathing}

Fetal development occurs in a state of relative hypoxia compared to the postnatal state, with fetal arterial $\mathrm{pO}_{2}$ of $\sim 20-30 \mathrm{mmHg}$ (versus adult alveolar arterioles $\mathrm{pO}_{2}$ of $\sim 100 \mathrm{mmHg}$ ) [29]. At birth, there is a rapid increase in oxygen tension after the baby's first breath which decreases expression of HIF-1 $\alpha$ [18]. HIF- $1 \alpha$ activity is mainly regulated by protein stability, with ubiquitination and subsequent degradation occurring rapidly in states of normoxia [30, 31]. In addition, lactate levels are relatively high in the fetus $(\sim 0.5-2 \mathrm{mM}$ in umbilical venous blood at 17-21 weeks gestation [32]) due to high glycolytic activity of the placenta [33], which decreases rapidly after birth $(\sim 0.5-1 \mathrm{mM}$ in umbilical venous blood at term delivery [32]) after achieving independence from placental circulation, with maternal arterial lactate levels of $0.68 \pm 0.07 \mathrm{mM}$ at delivery [34]. Lactate can also stabilize HIF-1 $\alpha$ in fibroblasts [35] and cancer cells 
independent of hypoxia [36]. HIF-1 $\alpha$ is required during embryonic development $[29,37]$, and deletion of HIF- $1 \alpha$ in mouse embryonic stem cells (ESCs) reduces cardiomyocyte differentiation efficiency, with reduced expression of sarcomere proteins [38].

However, during later stages of differentiation, inhibition of HIF- $1 \alpha$ has beneficial effects, enhancing contractile, electrophysiologic, and metabolic maturation of PSC-CMs and also leading to downregulation of LDH $[3,39]$. These differential effects during early and late cardiomyocyte differentiation reflect the changing role of HIFs at the time of birth and during the perinatal metabolic switch. Because in vitro culture is usually performed in atmospheric conditions, small molecules or metabolic stimuli have been used to inhibit HIF-1 $\alpha$ in culture (rather than manipulating oxygen levels). Treatment of human PSC-CMs with chetomin [3], FM19G11 $[39,40]$, or glucose-free, fatty acid-containing media [3] reduces HIF- $1 \alpha$ and LDH expression and improves maturation of PSC-CMs. Hypoxia promotes a perinuclear distribution of mitochondria to promote ROS-mediated nuclear regulation [24]. Chronic hypoxia promotes mitochondrial fusion while acute hypoxia promotes mitochondrial fission [24]; thus, shifts in mitochondrial dynamics initiated by HIF- $1 \alpha$ downregulation can alter mitochondrial function.

\section{Enteral nutrition and the metabolic switch}

Initiation of enteral nutrition in the perinatal transition initiates a metabolic switch from glycolysis to oxidative phosphorylation [41]. This metabolic switch is not merely a feature of mature cardiomyocytes, but a key driver that initiates cardiomyocyte differentiation and maturation [42, 43]. The high fatty acid composition found in breastmilk likely facilitates this metabolic switch [8]. In addition, Let-7 microRNA (miRNA), which is also abundant in breastmilk [44], can induce a metabolic switch from glycolysis to oxidative phosphorylation and enhance PSC-CM maturation [45]. Here, we describe how shifts in glucose and fatty acids affect maturation of cardiomyocytes.

\section{Glucose}

The fetus depends primarily on glucose for energy, relying on the maternal-fetal glucose gradient for nutrient transfer [46]. In the first $24 \mathrm{~h}$ after birth, glucose levels are relatively low, with plasma glucose levels as low as $30 \mathrm{mg} / \mathrm{dL}(1.7 \mathrm{mM})$, and then glucose increases to levels similar to adults (fasting levels $\sim 100 \mathrm{mg} / \mathrm{dL}$ or $5.6 \mathrm{mM}$ ) within the first few days of life after initiation of enteral feeding [47].

Pregnant mice or postnatal pups injected with ${ }^{18} \mathrm{~F}$-labeled FDG (glucose analog) demonstrated decreased uptake of ${ }^{18}$ F-FDG in hearts at 1 and 7 days after birth compared to E10.5, suggesting that reduced glucose uptake in the heart postnatally may facilitate cardiomyocyte maturation in vivo [48]. During pregnancy, maternal hyperglycemia can lead to fetal cardiomyopathy and increase the risk of congenital heart disease [49]. Mice born to hyperglycemic mothers have asymmetric cardiac hypertrophy but with decreased cardiomyocyte size and decreased expression of TNNT2, suggesting that hyperglycemia promotes excessive proliferation and delays cardiomyocyte maturation during development [48].

PSC-CMs also demonstrate a decrease in ${ }^{18}$ F-FDG uptake relative to ${ }^{125}$ I-BMIPP (fatty acid analog) uptake at $\sim 2$ weeks of cardiomyocyte differentiation that increases further to at least week 8 of differentiation, indicating that PSC-CMs undergo a metabolic switch from using glucose to fatty acids during differentiation [50]. Standard media used for culture of PSC-CMs in vitro often has supraphysiologic levels of glucose (DMEM $4.5 \mathrm{~g} / \mathrm{L}=$ $25 \mathrm{mM}$, DMEM/F12 $31.5 \mathrm{~g} / \mathrm{L}=17.5 \mathrm{mM}$, RPMI $2 \mathrm{~g} / \mathrm{L}=$ $11.1 \mathrm{mM}$ glucose versus physiologic levels of $\sim 5.5 \mathrm{mM}$ ). High glucose levels impair cardiomyocyte differentiation in both human [48] and mouse [51] ESCs, while upregulating genes associated with the cell cycle [48]. Suppressing glucose levels after cardiomyocyte specification enhances differentiation and maturation of PSC-CMs [3, 6,48 ] by reducing biosynthesis of nucleotides via the pentose phosphate pathway [48]. Both AMPK and mTOR systems are exquisitely sensitive to changes in glucose levels, leading to downstream regulation of mitochondrial dynamics, discussed further below.

\section{Fatty acids}

During gestation, fetuses receive nutrition that is low in fatty acids from the placenta. In contrast, breastmilk has a high fatty acid content, and the composition of the fatty acids changes over time to match the developmental needs of the newborn [52]. There is an increase in fatty acid serum content from $\sim 20 \mu \mathrm{M}$ as a fetus to $300 \mu \mathrm{M}$ as a newborn and $400 \mu \mathrm{M}$ as an adult [53].

Sub-physiologic concentrations of fatty acids can enhance PSC-CM maturation, and PSC-CMs only uptake about $1 / 3$ of fatty acids provided when at nearphysiologic concentrations in culture [4]. Human PSCCMs treated with $115.5 \mu \mathrm{M}$ fatty acids (palmitate-albu$\min (52.5 \mu \mathrm{M})$, oleic acid-albumin $(40.5 \mu \mathrm{M})$, and linoleic acid-albumin $(22.5 \mu \mathrm{M})$ ) for 2 weeks had increased size and force generation, increased mitochondrial respiratory reserve capacity, and increased action potential upstroke velocity compared to PSC-CMs not treated with fatty acids [4]. Similarly, PSC-CMs treated in glucose-free medium containing linoleic acid $(9.4 \mu \mathrm{g} / \mathrm{ml}$ or $33.5 \mu \mathrm{M})$, oleic acid $(9.4 \mu \mathrm{g} / \mathrm{ml}$ or $33.3 \mu \mathrm{M})$, and albumin $(1 \mathrm{mg} / \mathrm{ml})$ solution for 1 week exhibited more cell elongation, increased mitochondrial content, and 
increased basal oxygen consumption rate compared to control medium [54]. Palmitate $(100 \mu \mathrm{M})$ alone increased MLC2v expression and force of contraction, and its effects were further increased in low-glucose $(1 \mathrm{mM})$ solutions [6]. Without glucose, however, PSC-CMs cultured in fatty acid-rich medium experience lipotoxicity likely due to intracellular accumulation of fatty acids; addition of galactose $(10 \mathrm{mM})$ can prevent lipotoxicity while further improving oxidative capacity and cardiomyocyte maturation [55]. By promoting oxidative phosphorylation by mitochondria, fatty acid availability directly impacts mitochondrial function and downstream metabolite formation.

\section{Branched chain amino acids}

The shift to enteral nutrition also changes the composition of plasma amino acids. The branched chain amino acids (BCAAs), leucine, isoleucine, and valine, are obtained through the diet and can activate mTOR signaling to regulate insulin signaling [56]. Physiologic levels of BCAAs may be facilitate cardiomyocyte maturation through stimulation of mitochondrial biogenesis, but excessive levels of BCAA may be detrimental due to overactivation of mTOR signaling. Hyperglycemia induces cardiomyocyte death in diabetic rats, and this may be due to abnormalities in metabolism of branched chain amino acids [57]. Hyperglycemia downregulates enzymes involved in catabolism of branched chain amino acids via inhibition of Krüppel-like factor 15 (KLF15), leading to intracellular accumulation of BCAAs, mTOR overactivation, and cardiomyocyte hypertrophy [58]. Chronic administration of water supplemented with branched chain amino acids can stimulate mitochondrial biogenesis, increase sirtuin 1 expression, and decrease ROS levels in cardiomyocytes while prolonging lifespan in mice [59]. Similarly BCAA supplementation can protect against doxorubicin-induced mitochondrial dysfunction and ROS production in cardiomyocytes [60].

\section{Hormone systems}

Maturation of the endocrine system occurs simultaneously with cardiac development, leading to increases in fetal serum concentrations of hormones such as thyroid hormone or corticosteroids throughout fetal development. In addition, withdrawal of maternal estrogen after birth and alterations in retinoid signaling with enteral feeding may also play roles in cardiomyocyte maturation.

\section{Insulin}

Insulin levels are relatively high during the fetal state but decrease in the newborn before stabilizing to adult levels [53]. Insulin receptor and insulin-like growth factor 1 (IGF1) receptor facilitate cardiomyocyte proliferation starting at embryonic day E10.5 [61]. In PSCs, early insulin $(10 \mathrm{mg} / \mathrm{L})$ treatment at the start of differentiation can inhibit cardiomyocyte formation, directing cells instead toward a neuroectoderm phenotype [62]. However, insulin does not inhibit cardiomyocyte differentiation induced by Wnt signaling, due to counteractive effects of $\beta$-catenin on insulin signaling [63]. Insulin/IGF1 treatment after cardiomyocyte formation increases proliferation and yield [64, 65], and combined IGF1 and neuregulin-1 (NRG1) treatment of PSC-CMs improves metabolic and contractile maturation [66]. Insulin activates $\mathrm{mTOR}$ signaling in the presence of glucose [67] and can also inhibit cardiomyocyte apoptosis [68] and promote mitochondrial fusion and enhance function by upregulation of OPA1 [69].

\section{Triiodothyronine}

Human fetal serum levels of total and free tri-iodo-Lthyronine (T3) and thyroxine (T4) and thyroxinebinding globulin increase throughout gestation, with total and free T4 and thyroxine-binding globulin levels reaching that of adults by 36 weeks gestation [70]. T3 serum levels remain well below maternal levels throughout gestation [70], with late fetal total T3 levels $\sim 1-1.5$ $\mathrm{nM}(65-98 \mathrm{ng} / \mathrm{dL})$ and maternal levels $\sim 2.5-3.5 \mathrm{nM}$ (160-230 ng/dL), with mean non-pregnant adult levels $\sim 2.1 \mathrm{nM}(137 \mathrm{ng} / \mathrm{dL})$ [70]. Congenital hypothyroidism is associated with cardiac defects, with $18.5 \%$ of congenital hypothyroidism infants having congenital heart disease in one study [71].

T3 has direct effects on cardiomyocyte development. T3 accelerates terminal differentiation and maturation of ovine fetal cardiomyocytes in vitro [72], and infusion of T3 during late gestation in sheep fetuses enhances cardiomyocyte binucleation, reduces cardiomyocyte proliferation (with increased p21 and decreased cyclin D1 expression), increases expression of SERCA2a, and increases cardiomyocyte size [73] via signaling through thyroid hormone receptors (TR) located in the nucleus [74]. Deletion of TR $\alpha 1$ in mice leads to bradycardia and reduced contractility with decreased myosin heavy chain $\alpha(\mathrm{MHC} \alpha)$ and SERCA2 expression, while deletion of TR $\beta 1$ in mice leads to tachycardia and no change in contractility [75]. T3 activates AMP-activated protein kinase (AMPK) leading to increased protein synthesis, while AMPK attenuates T3-induced cardiomyocyte hypertrophy in neonatal rat ventricular cardiomyocytes [76]. T3 rapidly induces an increase in AMPK activators (LKB1 (liver kinase B1) and CaMKK2 $\beta$ (calcium/calmodulin-dependent protein kinase kinase 2) and AMPK suppressors (PP2C (protein phosphatase 2C)), suggesting that narrow regulation of AMPK activity is required for normal cardiomyocyte development [76]. T3 can also reduce ROS following ischemia/reperfusion injury in mice 
and reduce $\mathrm{H}_{2} \mathrm{O}_{2}$-induced mitochondrial dysfunction and oxidative stress by increasing expression of the transcription factor, Nrf2, which increases expression of antioxidants such as HO-1, and activation of the PI3K/ AKT signaling pathway [77].

Treatment of PSC-CMs with supraphysiologic levels of T3 $(20 \mathrm{ng} / \mathrm{ml}=2000 \mathrm{ng} / \mathrm{dL}=30.7 \mathrm{nM})$ for 1 week starting after 20 days of differentiation increased cardiomyocyte size, increased expression of the cell cycle inhibitor p21, enhanced contractility, and increased oxygen consumption rate [5]. In another study, use of even higher levels of T3 $(100 \mathrm{nM})$ for 2 weeks did not increase Ttubule formation unless combined with dexamethasone [78], thus synergy with other metabolic systems is likely necessary to observe maximal effects. Similarly, combined treatment with glucose-free medium containing T3 (10 nM) and fatty acids (linoleic and oleic acids) for up to 9 days exhibit a higher upstroke velocity, increased isoproterenol sensitivity, and decreased proliferation [79].

\section{Glucocorticoids}

Glucocorticoids are steroid hormones that act via the glucocorticoid receptor. Serum cortisol levels are low during mid-gestation ( $4 \mathrm{ng} / \mathrm{mL}$ at $17.5-20$ weeks) but increase at term $(45 \mathrm{ng} / \mathrm{mL}$ by 40 weeks) and increase sharply at delivery (mean $114 \mathrm{ng} / \mathrm{mL}$ in term infants at delivery) [80] before declining to basal levels (mean $\sim 65$ $\mathrm{ng} / \mathrm{mL}$ in healthy infants) [81]. Global glucocorticoid receptor deficiency also prevents maturation of the heart in rats, with $\mathrm{GR}^{-/-}$rats having disorganized myofibrils, reduced diastolic function, and fetal edema characteristic of hydrops fetalis [82], while maternal glucocorticoid administration prior to preterm piglet delivery enhances cardiomyocyte maturation [83].

Several treatment strategies have demonstrated PSCCM maturation with dexamethasone. Dexamethasone $(1 \mu \mathrm{mol} / \mathrm{L}=392 \mathrm{ng} / \mathrm{mL}, 24-72 \mathrm{~h})$ promotes electrophysiologic maturation of hESC-CMs with accelerated calcium transient decay, enhanced function of the $\mathrm{Na}^{+}$$\mathrm{Ca}^{2+}$ exchanger (NCX) and sarco-endoplasmic reticulum calcium-ATPase (SERCA), and enhanced contractility [84]. Similarly, treatment of PSC-CMs with a combination of dexamethasone $(1 \mu \mathrm{M})$ and $\mathrm{T} 3(100 \mathrm{nM})$, with $[39,85]$ or without [78] insulin-like growth factor 1 (IGF-1; $100 \mathrm{ng} / \mathrm{mL}$ ) for $1-2$ weeks promotes cardiomyocyte maturation. While glucocorticoids are important in normal cardiac development, they can also have detrimental effects in other models [86]-for example, chronic, supraphysiologic doses of glucocorticoids can increase the risk of cardiovascular disease in adults [87] - thus, further work is necessary to understand the optimal duration of treatment to maximize PSC-CM maturation without inducing deleterious effects of glucocorticoids.

The mechanism by which dexamethasone acts may be through mitochondrial maturation. Activation of the glucocorticoid receptor upregulates expression of PPAR $\gamma$ (peroxisome proliferator-activated receptor $\gamma$ ) coactivator $1 \alpha(\mathrm{PGC}-1 \alpha)$ [88], a transcriptional coactivator that induces mitochondrial biogenesis and maturation [89]. Furthermore, short-term $(24 \mathrm{~h})$ dexamethasone treatment promotes maturation and inhibits proliferation of mouse ESC-CMs via mitochondrial aggregation of LC3 and induction of Parkin-mediated mitophagy [90]. Parkin-mediated mitophagy selectively degrades dysfunctional or depolarized mitochondria via autophagic processes activating the ubiquitin-proteasome system [91]. Thus, the combination of enhanced mitochondrial biogenesis, mitochondrial maturation, and elimination of dysfunctional mitochondria likely promotes glucocorticoid-induced cardiomyocyte maturation.

\section{Estrogen}

Estrogen levels are relatively high during fetal development due to maternal hormones, with estrogen withdrawal occurring within the days after birth [92]. Signaling through estrogen-related receptors $\alpha$ and $\gamma$ $(E R R \alpha / \gamma)$ enhances maturation of cardiomyocytes during development [93], and ERR $\gamma$ is involved in regulation of the metabolic switch to oxidative metabolism in the heart [94]. Deletion of ERR $\alpha / \gamma$ in mice leads to cardiomyopathy with arrested maturation of mitochondria, while ESRRA and ESRRA deletion in human PSC-CMs downregulates expression of non-cardiac genes, including those consistent with a fibroblast phenotype such as TCF21, periostin, and collagen type III [93].

\section{Retinoic acid}

Retinoids are the family of compounds derived from vitamin A [95]. The main biologically active metabolite, all-trans retinoic acid (ATRA) (also known as tretinoin), is formed by oxidation of retinol and signals via retinoic acid receptors (RAR) located in the nucleus [95]. RAR forms a heterodimer with retinoid X receptor (RXR) that then binds to retinoic acid response elements (RAREs) to regulate gene expression [96]. Serum ATRA concentration is lower in human newborns $(3.4 \mathrm{nmol} / \mathrm{L})$ than mothers immediately post-partum $(5.8 \mathrm{nmol} / \mathrm{L})$ and in control (non-pregnant or post-partum) women (5.2 $\mathrm{nmol} / \mathrm{L})$ [97].

Isolated deletion of RAR $\alpha$ [98], RAR $\beta$ [99], or RAR $\gamma$ [100] does not affect cardiac development, although double knockout of RAR $\alpha$ with either RAR $\beta$ or RAR $\gamma$ led to a high incidence of structural heart disease [101, 102]. Deletion of RXR $\alpha$ leads to ventricular failure during embryonic development [103]. Interestingly, 
excessive levels of vitamin A during development is teratogenic and can also increase the risk of congenital heart disease [104, 105]. RAR or RXR agonists prevent cardiomyocyte apoptosis and cardiac fibrosis induced by hyperglycemia in rat cardiomyocytes [106] via activating liver kinase B1 (LKB1) signaling and inhibiting p70 ribosomal protein S6 kinase activity (p70S6K) [107]. LKB1 is a key player in metabolic regulation through activation of AMPK, which can in turn inhibit the mTOR signaling pathway, and p70S6K is immediately downstream of mTOR complex 1 (mTORC1) [108]. Thus, retinoid signaling is closely tied to metabolic transitions that occur after birth with a shift in nutrient type and availability.

Treatment of PSC-CMs with supraphysiologic levels of ATRA $(1 \mu \mathrm{mol} / \mathrm{L})$ during early differentiation (days $2-4$, mesoderm stage) increased expression of cardiac markers TNNT2, NKX2.5, and MYH6 by day 10, while treatment with retinoic acid from days 15-20 of differentiation enhanced cardiomyocyte size, increased action potential duration, and increased mitochondrial content and maximal respiration capacity [109]. Duration and dose of retinoic acid appear to be important factors in directing cardiomyocytes toward their desired phenotype, as treatment with $500 \mathrm{nmol} / \mathrm{L}$ ATRA from days 312 of differentiation leads to specification of an atrial cardiomyocyte phenotype rather than ventricular cardiomyocyte maturation [110].

\section{Angiotensin II}

Angiotensin II is a peptide hormone that regulates vasomotor tone and blood pressure and can enhance contractility [111]. Circulating levels of angiotensin II increase throughout fetal development and peak shortly after birth $[112,113]$. Autoantibodies to angiotensin type 1 receptor (AT1R) during fetal development have decreased cardiac function with unorganized myofibrils and increased expression of proteins involved in glycolysis [114]. Crosstalk between the renin-angiotensin system and AMPK [115] may link angiotensin II to metabolic transitions occurring during cardiomyocyte development. Angiotensin II acts via the AT1R to promote differentiation of mouse ESC-CMs via c-Jun NH2terminal kinase (JNK) and activation of the mitogenactivated protein kinase (MAPK) pathway leading to upregulation of sarcomere proteins and cardiomyocyte hypertrophy [116, 117]. Angiotensin II upregulates glucose uptake and mTOR signaling while downregulating AMPK activation leading to cardiac hypertrophy, while use of an AMPK activator increases fatty acid uptake and prevents cardiomyocyte hypertrophy [118]. These findings suggest that angiotensin II regulates early cardiomyocyte development through upregulation of sarcomere proteins but may have detrimental effects later by interruption of fatty acid metabolism.

\section{Noncoding RNAs}

Noncoding RNAs, in particular microRNAs (miRNAs) ( 18-24 nucleotides) and long noncoding RNAs (lncRNAs) (>200 nucleotides), can be affected by changes in nutrient availability [119-121]. MicroRNAs (miRNAs) (18-24 nucleotides) can also regulate mitochondrial function, cellular quiescence, and maturation through epigenetic mechanisms involving posttranscriptional regulation of mRNA [25, 122]. A review of all miRNAs is beyond the scope of this review, but we highlight miR-1 as an example. Mice deficient in miR-1 have both structural and electrophysiological cardiac defects [123]. During differentiation of mouse ESC-CMs, miR-1 expression is upregulated, and overexpression of miR-1 can promote formation of cardiac mesoderm during early differentiation by suppression of WNT and FGF pathways [124, 125]. However, overexpression of miR-1 in adult rats increases the risk of ventricular arrhythmias by downregulating Kir2.1 (encoded by $\mathrm{KCNJ} 2$ ) and $\mathrm{Cx} 43$ leading to reduced conduction and cardiomyocyte depolarization [126]. While miR-1 can enhance ATP production in mitochondria, it is upregulated during senescence [127]. MiR-1 expression is increased in Hutchinson-Gilford progeria, a disease of accelerated aging [128]. While low levels of ROS $(30 \mu \mathrm{M}$ $\mathrm{H}_{2} \mathrm{O}_{2} \times 2$ days) can decrease miR-1 expression via ERK phosphorylation, high levels of ROS $(200 \mu \mathrm{M} \times 6 \mathrm{~h})$ can increase miR-1 via JNK phosphorylation in neonatal rat ventricular cardiomyocytes [129]. Furthermore, miR-1 exacerbates oxidative stress by reducing expression of antioxidant proteins in cardiomyocytes [130]. In addition, nutrient signals likely affect miR-1 expression, as inhibition of mTOR signaling in skeletal muscle represses miR-1 expression [131]. Hyperglycemia increases expression of miR-1 via p38 MAPK, leading to mitochondrial dysfunction, downregulation of $\mathrm{Cx} 43$, and cardiomyocyte apoptosis [132, 133], and these effects can be ameliorated by upregulation of liver $\mathrm{X}$ receptor $\alpha$ (LXR $\alpha)$ [134]. These studies demonstrate that fine tuning of multiple miRNA levels through nutrient availability is important to promote cardiomyocyte development.

In addition, long noncoding RNAs (> 200 nucleotides) are involved in both the pathophysiology of cardiac diseases [135] and cardiac development. For example, the lncRNA, Hand2os1, regulates the transcription factor, $H A N D 2$, to control cardiac morphogenesis during early development [136]. LncRNA expression is deregulated during states of metabolic stress such as in diabetes and altered expression patterns can be associated with development of diabetic cardiomyopathy [137]. Conversely, nutrient deprivation can acutely change expression levels of lncRNAs in skeletal muscle [138]. There are dynamic expression levels of lncRNAs in the heart, changing during the first week of life, suggesting an important role 
for lncRNAs in postnatal cardiomyocyte maturation [139].

\section{O-GIcNAcylation}

O-GlcNAcylation is a post-translational modification analogous to phosphorylation that is regulated by nutrient availability and cellular stress [140-142] O-linked Nacetylglucosamine (O-GlcNAc) is a product of the hexosamine biosynthetic pathway that attaches to serine and threonine protein residues by O-GlcNAc transferase (OGT) and can be removed by O-GlcNAcase (OGA) [140]. Dysregulation of O-GlcNAc glycosylation adversely affects mitochondrial function [143]. Loss of OGT during development leads to dilated cardiomyopathy and abnormal coronary artery formation in mice [144]. OGT is required for maturation of postnatal cardiomyocytes by maintaining homeostasis of the endoplasmic reticulum and mitochondria [145] and is required for autophagy in cardiomyocytes [146]. However, excessive O-GlcNAcylation inhibits cardiomyocyte differentiation in ESCs [147]. Acutely increasing OGlcNAcylation can be cardioprotective during ischemia in neonatal cardiomyocytes [148]; however, chronic elevation of O-GlcNAcylation as seen in diabetes leads to cardiac dysfunction and increase risk of arrhythmias via activation of $\mathrm{Ca}^{2+} /$ calmodulin-dependent protein kinase II (CaMKII) [149, 150]. Thus, time-dependent or stagespecific regulation of O-GlcNAcylation may have opposing effects in cardiomyocytes.

\section{Metabolic regulation of mitochondria}

Given their central role in maintaining the metabolic phenotype, mitochondrial maturation may not simply be a byproduct of overall cardiomyocyte maturation but may actually drive cardiomyocyte maturation [151]. Metabolic shifts during fetal development and at birth target mitochondrial molecular pathways such as mitochondrial biogenesis, fission/fusion, mitophagy, and the mitochondrial permeability transition pore (Fig. 2).

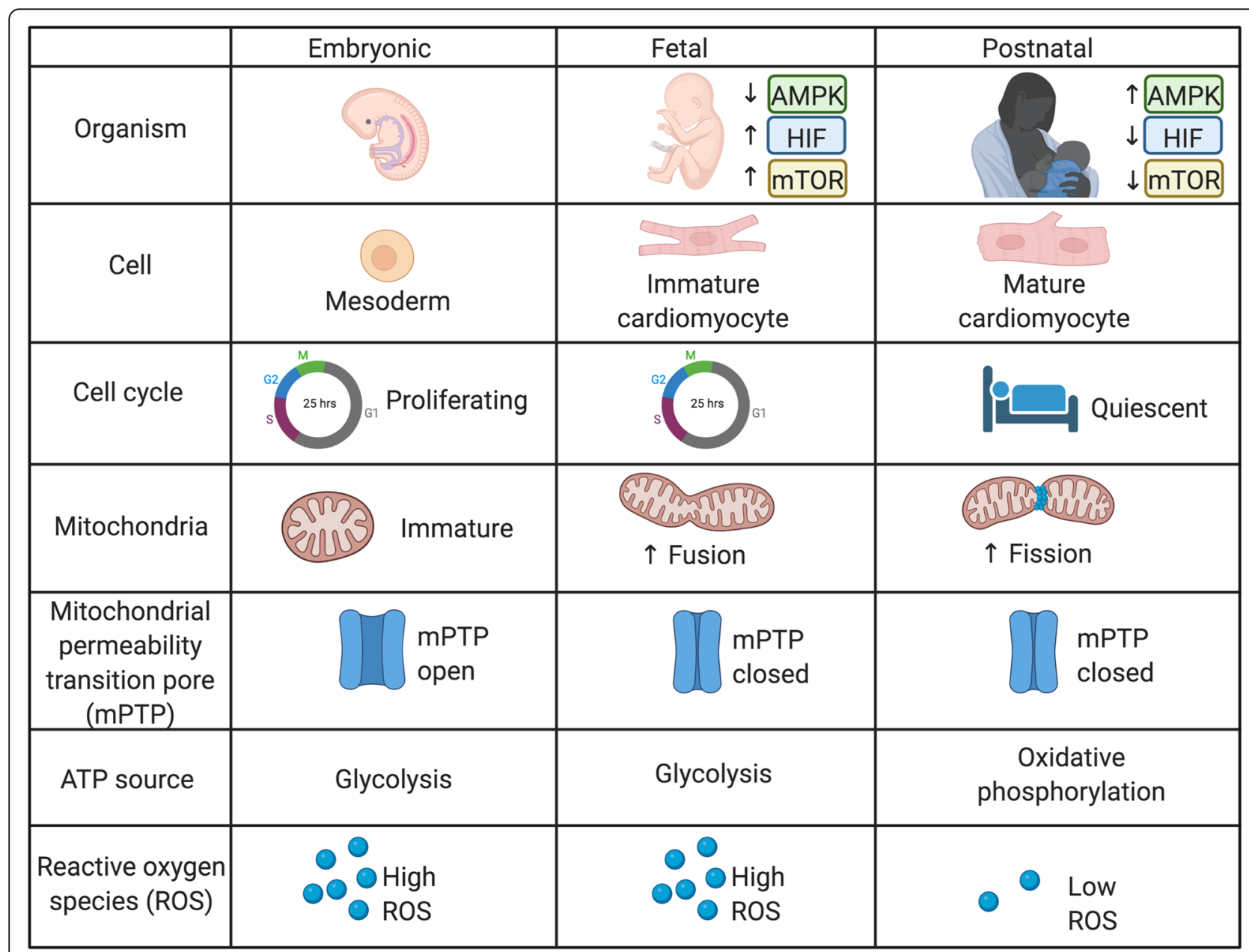

Fig. 2 Metabolic transitions during development. Metabolic transitions from the embryonic to fetal to postnatal states regulate mitochondrial morphology and function, cell cycle state, cardiomyocyte maturation, and metabolite production 


\section{Mitochondrial biogenesis}

Mitochondria in mature cardiomyocytes are large, occupying $\sim 1 / 3$ of the cardiomyocyte volume, and are organized between myofibrils (intermyofibrillar), beneath the sarcolemma (subsarcolemmal) or near the nucleus (perinuclear) [152]. In contrast, fetal mitochondria are smaller, have less well-defined cristae, and are poorly organized, distributed throughout the cytoplasm during early development, although they begin to relocate between myofibrils during later fetal development [152, 153]. Mitochondrial biogenesis that occurs during late fetal and early neonatal development is necessary to drive cardiomyocyte maturation [154].

Peroxisome proliferator-activated receptor gamma coactivators $1 \alpha$ (PGC- $1 \alpha)$ and $1 \beta$ (PGC-1 $\beta)$ are transcriptional coactivators that play key roles in mitochondrial biogenesis [154] and can be activated by AMPK [49]. PGC- $1 \alpha^{-/-}$or PGC-1 $\beta^{-/-}$mice have mild cardiac dysfunction, but double deletion of PGC- $1 \alpha \beta^{-1-}$ leads to neonatal death with bradycardia, heart block, and cardiac dysfunction [154]. PSC-CMs upregulate PGC- $1 \alpha$ during differentiation [155]. Activation of PGC- $1 \alpha$ with ZLN005 improves maturation of PSC-CMs [89], while overexpression of PGC- $1 \alpha$ in H9c2 cells stimulates mitochondrial biogenesis and autophagy to protect against lipopolysaccharide-induced apoptosis [156]. Contractile work requires increased ATP levels and this may also trigger enhanced mitochondrial biogenesis [157]. In addition, elevated glucose levels inhibit AMPK signaling which can adversely affect mitochondrial biogenesis and dynamics; activation of AMPK with berberine can reverse hyperglycemia-induced effects, leading to enhanced mitochondrial function by stimulating biogenesis and promoting mitophagy of dysfunctional mitochondria [158]. MiR-144 is decreased in hyperglycemic conditions, but overexpression of miR-144 can promote mitochondrial biogenesis and reduce apoptosis via AMPK phosphorylation and PGC1 $\alpha$ deacetylation [159].

\section{Mitochondrial fission and fusion}

Mitochondria are dynamic organelles, undergoing processes of fusion and fission to maintain cardiac function (Fig. 3). Fission is regulated by PINK1/Parkin to signal the GTPase dynamin-related protein, DRP1 (encoded by DNM1L), to assemble into a constrictive ring to sever a mitochondrion into two halves [160]. Fusion occurs in

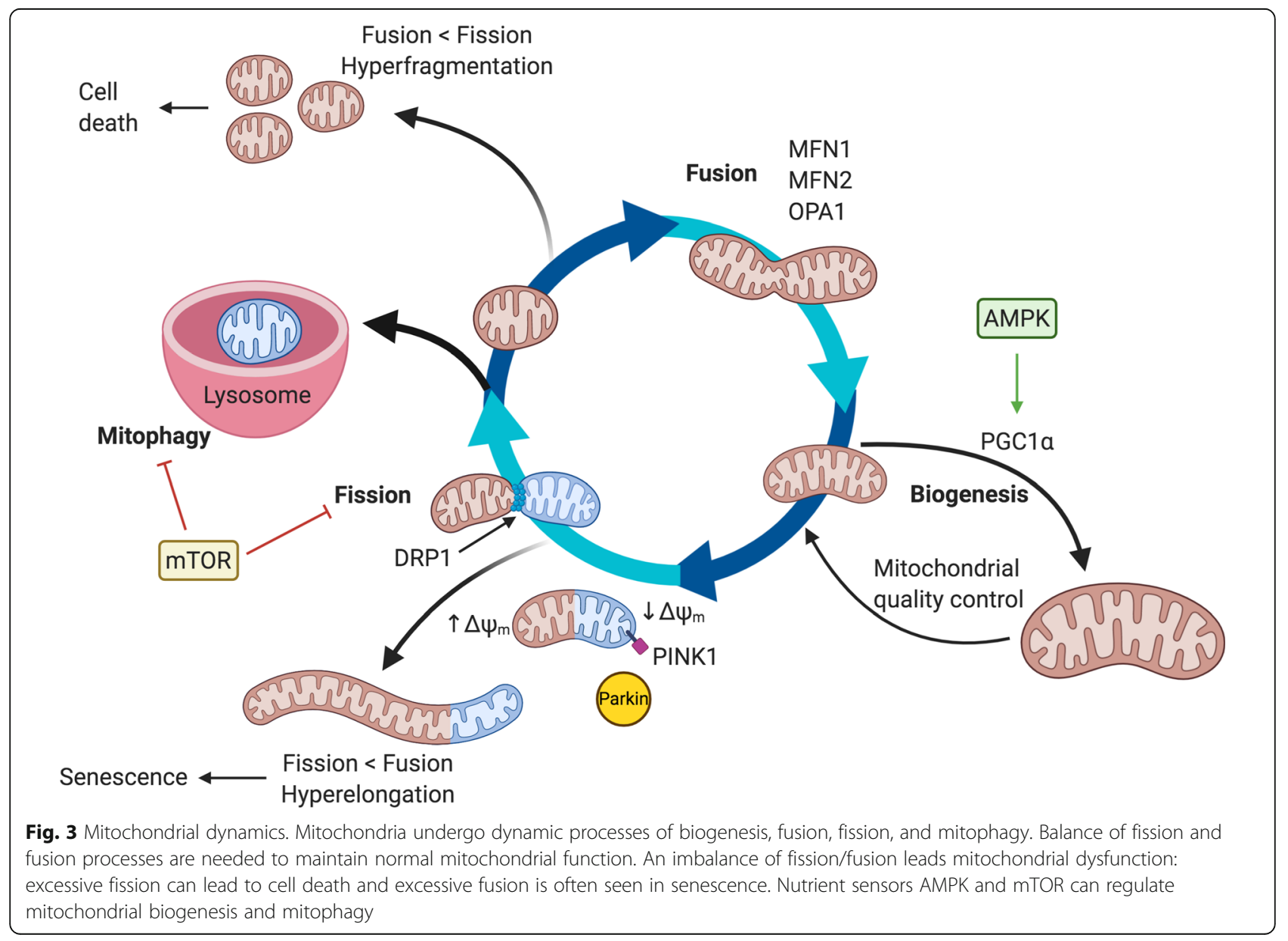


two steps, first with fusion of the outer mitochondrial membrane (OMM) via mitofusins 1 and $2(\mathrm{MFN}-1 / 2)$, followed by fusion of the inner mitochondrial membrane (IMM) via interactions between optic atrophy 1 (OPA1) and cardiolipin [161]. In adult cardiomyocytes, mitochondrial dynamics are constrained by spatial limitations imposed by myofibrils [162], but changes in mitochondrial morphology are important in regulating developmental processes and in diseased states [163].

Isolated cardiomyocyte deletion of either $M f n 1$ [164] or $M f n 2$ [165] in mice promotes mitochondrial fragmentation that actually has a cardioprotective effect under stress conditions, but combined deletion of both Mfn1 and Mfn2 in cardiomyocytes is embryonic lethal by day E9.5 [166]. Similarly, cardiomyocyte deletion of Dnm1l in mice is lethal by 6 weeks of age [167]. Postnatal cardiomyocyte deletion of Mfn1/Mfn2 in mice leads to mitochondrial fragmentation and hypertrophic cardiomyopathy with left ventricular dilation leading to death within 2-3 months [166], while Drp1 deletion leads to mitochondrial hyperelongation, cardiomyocyte necrosis, and a dilated cardiomyopathy phenotype with fulminant heart failure within 3-6 weeks leading to death [167]. Triple knockout of Drp1/Mfn1/Mfn2 remarkably delays the lethal effects of Drp1 deletion alone or Mfn1/Mfn1 deletion alone, exhibiting a concentric cardiac hypertrophy eventually leading to death between 3 and 6 months after tamoxifen treatment [168]. These findings demonstrate that an imbalance in fission and fusion processes causes more harm than when both processes are downregulated together.

OPA1 is a dynamin-like guanosine triphosphatase (GTPase) located in the inner mitochondrial membrane. Opa1 overexpression preserves mitochondrial function and prevents cardiomyocyte apoptosis after hypoxic injury through decreasing fission, increasing fusion, increasing mitophagy, and increasing mitochondrial biogenesis [169]. The full-length protein of OPA1 (long OPA1, or L-OPA1) facilitates mitochondrial fusion and is required during embryonic development [170]; however, OPA1 can be cleaved by two mitochondrial proteases, OMA1 or YME1L, to convert from L-OPA1 to a short form (S-OPA1), which reduces mitochondrial fusion and enhances fission [171].

During early differentiation, inhibition of fission and/ or promotion of fusion may enhance differentiation efficiency, while promotion of fission may facilitate postnatal maturation. Mitochondrial elongation occurs during mouse ESC-CM differentiation, and downregulation of MFN2 or OPA1 prevents cardiomyocyte differentiation with reduced expression of Nkx2.5, Gata4, and Mef2c2 [172]. Furthermore, mitochondrial elongation prevents overactivation of calcineurin and Notch1 signaling to allow the transition from mesoderm to cardiomyocyte to occur normally, thus mitochondrial shape directly influences early cardiomyocyte development [172]. Promotion of fusion during PSC-CM differentiation increases the percentage of embryoid bodies that are beating and increases expression of cardiac genes [173, 174]. However, mitochondrial fission may be important in cardiomyocyte maturation during the neonatal period as mice deficient in Drp1 have disorganized myofibrils, reduced mitochondrial respiration, and abnormal cardiac function postnatally [175]. Wild-type mice have high expression of Drp1 in neonatal hearts at postnatal day 7 (P7) that decreases until mice are 4 weeks of age [175]; thus, a shift from a mitochondrial fusion to fission appears to accompany the metabolic switch that occurs postnatally and may be an important window for promoting cardiomyocyte maturation.

Mitochondrial fission and fusion processes are sensitive to intracellular and extracellular substrates; understanding how to fine tune the precise dynamics between the two processes is not well understood. Nutrients such as glucose or lipids can either activate or inhibit mitochondrial fission depending on context, and these processes are also regulated by post-translational modifications [176]. High glucose increases opening of the mitochondrial permeability transition pore (mPTP), ROS production, fission, and cell death [177-179]. However, removal of glucose of neonatal rat ventricular cardiomyocytes in culture can also increase Drp1 activation via S616 phosphorylation leading to mitochondrial fission and enhanced mitophagy [180] and reduced cell viability by $48 \mathrm{~h}$ [181]. While one interpretation of these in vitro results is that DRP1 activation in low-glucose conditions is detrimental to cardiomyocyte viability via increased autophagic processes, it may be that monolayer culture conditions in vitro affect the balance of mitochondrial dynamics, and Drp1 activity is inadequately balanced by fusion processes in vitro. Homozygous Drp1 deletion in adult mice leads to accumulation of elongated, dysfunctional mitochondria, reduced mitophagy, ventricular dysfunction, and death by $\sim 3$ months [180]. DRP1 activation may actually be a beneficial response under conditions of energy stress that is cardioprotective in vivo when fission and fusion processes are differently balanced compared to in vitro conditions. However, in streptozotocin-induced diabetic mice, inhibition of Drp1-mediated fission with melatonin improved mitochondrial function and reduced $\mathrm{O}_{2}{ }^{-}$production in the heart via upregulation of SIRT1 and PGC1 $\alpha$ [182]. Another theory is that DRP1 activation may be detrimental under conditions of chronic hyperglycemia while it may be beneficial in periods of acute fasting, thus culture of cells in high glucose media prior to the start of an experiment may affect the balance of mitochondrial fission and fusion processes that is different from 
physiologic conditions. Besides glucose, insulin can promote fusion [69], while a high-fat diet or elevated intracellular calcium levels increase fission [183, 184]. Nutrient shifts during the immediate postnatal period may have profound impacts on mitochondrial shape, which then can have downstream effects by altering mitochondrial biogenesis, mitophagy, metabolite production, and cell cycle regulation.

\section{Mitochondrial permeability transition pore}

The MPTP is a conductance channel found in the inner mitochondrial membrane that permits equilibration of solutes less than $1.5 \mathrm{kDa}$ in size [185]. During early heart development, mouse embryonic cardiomyocytes exhibit mitochondrial maturation between embryonic days E9.5 and E13.5, with closure of the MPTP, increased polarization of the mitochondrial membrane potential $\left(\Delta \Psi_{\mathrm{m}}\right)$, decreased ROS levels, and development of more mitochondrial cristae [186]. Pharmacologic closure of the mPTP in E9.5 but not E11.5 or E13.5 myocytes using cyclosporine A $(500 \mathrm{nM}, 2 \mathrm{~h})$ triggers mitochondrial maturation, resulting in mitochondrial elongation, increased $\Delta \Psi_{\mathrm{m}}$, and decreased ROS, as well as an increased number of myocyte $\mathrm{Z}$ bands suggestive of concomitant cardiomyocyte maturation [186]. Similarly, treatment of neonatal mouse cardiomyocytes with cyclosporine A to induce MPTP closure increased $\Delta \Psi_{\mathrm{m}}$, decreased ROS levels, and increased cardiomyocyte size, while treatment of neonatal mice from postnatal days 15 with cyclosporine A increased left ventricular ejection fraction [187], suggesting further maturation of cardiomyocytes occurs postnatally through this mechanism. Treatment of mouse or human ESC-CMs with cyclosporine A $(2 \mu \mathrm{g} / \mathrm{mL}$, days $4.5-10.5$ of differentiation) or NIM811 $(3.6 \mu \mathrm{g} / \mathrm{mL})$, which also closes the mPTP, increased $\Delta \Psi_{\mathrm{m}}$, increased RNA expression of genes associated with cardiomyocyte differentiation and mitochondrial function, and increased the percent of TNNT2+ cardiomyocytes produced [188].

The MPTP state can be affected by nutrient availability, calcium and ROS, and can affect insulin sensitivity. High calcium or ROS levels trigger mPTP opening, loss of $\Delta \Psi_{\mathrm{m}}$, mitochondrial swelling, and subsequent cell death [189]. Mitochondrial fusion proteins, MFN1 and MFN2, can promote mPTP opening [164, 165]. In a mouse model of ischemia reperfusion injury, inhibition of the nutrient sensor AMPK leads to MPTP opening during reperfusion, leading to increased ROS production and necrosis [190]. In addition, Parkin, a key regulator of mitochondrial mitophagy, can be upregulated by AMPK [191] and can also inhibit mPTP opening and prevent necrosis in cardiomyocytes by targeting cyclophilin $\mathrm{D}(\mathrm{CypD})$, a key component involved in opening of the MPTP [192]. Thus, targeted closure of the MPTP may be important for PSC-CM maturation (Fig. 4).

\section{Mitophagy}

Autophagy of mitochondria, or mitophagy, is important to maintain mitochondrial quality control mechanisms through removal of dysfunctional mitochondria. The PINK1/Parkin system is responsible for initiation of this process: PINK1 accumulates in depolarized (dysfunctional) mitochondria, which recruits Parkin to the mitochondrial surface [193]. Parkin is an E3 ubiquitin ligase that ubiquitylates outer mitochondrial proteins to target it for proteasome degradation [194]. Deletion of Parkin between birth and weaning in mice prevents postnatal cardiomyocyte maturation, with impaired mitochondrial biogenesis and inhibition of fatty acid oxidation [195].

Mitophagy can be regulated by nutrient sensing systems such as Akt/mTOR signaling (upregulated in high nutrient states) or AMPK signaling (upregulated in fasting states) [196, 197]. Inhibition of mTOR signaling with simvastatin increases mitochondrial fission and mitophagy in HL-1 cardiomyocytes and is cardioprotective following myocardial infarction in wild-type mice [198]. Conversely, the AMPK $\alpha 2$ isoform phosphorylates PINK1 at Ser495 to remove dysfunctional mitochondria via enhanced mitophagy and protect against pressure overload in the heart [199]. Mitochondrial depolarization and subsequent mitophagy can also be caused by opening of the mPTP, which can be regulated by AMPK [167]. Upregulating fatty acid oxidation through deletion of acetyl coenzyme A carboxylase 2 (ACC2) promotes Parkinmediated mitophagy and prevents myocardial dysfunction caused by a high-fat diet [200]. Thus the metabolic shift toward oxidative phosphorylation provides positive feedback to further hone mitochondrial quality control mechanisms through enhancing mitophagy. In contrast, inhibition of mitophagy via chronic activation of monoamine oxidase-A (MAO-A) leads to accumulation of cytosolic p53 and inhibition of Parkin, with subsequent reduction in mitophagy and retention of dysfunctional mitochondria [201]. MAO-A activation also leads to upregulation of cell cycle inhibitors, induction of the ROS-induced DNA damage response, and increased activity of senescence-associated $\beta$ galactosidase (SA- $\beta$ gal), consistent with a senescent phenotype. Maintaining mitophagy may inhibit senescence and promote cardiomyocyte maturation.

\section{Molecular consequences of mitochondrial transformations}

Reactive oxygen species

Reactive oxygen species (ROS), including superoxide anion $\left(\mathrm{O}_{2}^{-}\right)$, hydrogen peroxide $\left(\mathrm{H}_{2} \mathrm{O}_{2}\right)$, and hydroxy radical $(\cdot \mathrm{OH})$, are produced during oxidative 


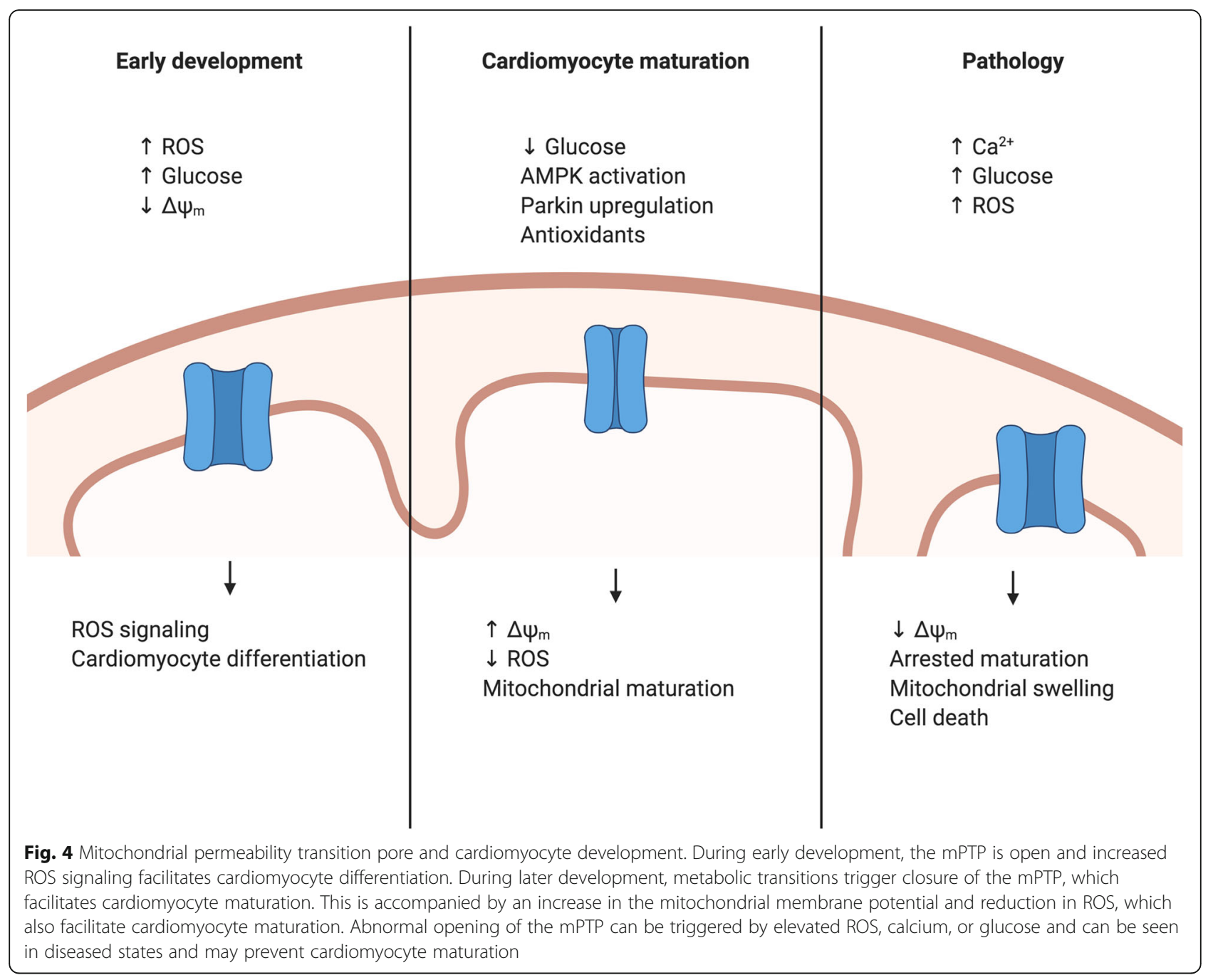

phosphorylation and can have downstream signaling effects in cardiomyocytes via redox effects [202]. At physiologic levels, oxidation of selected proteins can maintain normal cellular function, but in excess, nonspecific oxidation of cellular contents can be toxic [203]. Oxidation of miRNAs such as miR-1 can lead to their inactivation and subsequent dysregulation of mRNA expression in the heart [204]. The role of ROS signaling during cardiomyocyte differentiation and maturation is context-dependent. During early differentiation of mouse ESC-CMs, transient increases in ROS with $\mathrm{H}_{2} \mathrm{O}_{2}$ or menadione improves cardiomyocyte differentiation with enhanced expression of sarcomere genes and improved contractility [205, 206]. Similarly, elevated glucose levels $(25 \mathrm{mM})$ increases ROS formation in early PSC-CM differentiation compared to physiological levels $(5 \mathrm{mM})$, and high glucose and high ROS promote cardiomyocyte differentiation, while low-glucose or early antioxidant treatment prevents cardiomyocyte differentiation [206,
207]. Upregulation of PGC1 $\alpha$ during PSC-CM differentiation increases mitochondrial size and respiratory capacity while also increasing ROS production [208]. However, in mouse embryonic cardiomyocytes at embryonic day E9.5, antioxidant treatment enhances while oxidant treatment impairs cardiomyocyte differentiation [186]; this developmental stage also coincides with closure of the mPTP [186]. Furthermore, while knockdown of PGC1 $\alpha$ impairs mitochondrial function, the concomitant reduction in ROS actually increases the action potential amplitude and duration closer to those seen in mature adult cardiomyocytes [208], possibly by preventing ROS-induced decreases in $\mathrm{Ca}^{2+}$ influx [209] or increases in $\mathrm{K}^{+}$efflux [210]. Thus, the effects of ROS appear to be timedependent: early ROS production may facilitate initiation of cardiomyocyte differentiation and sarcomere formation, while reduction of ROS levels after cardiomyocyte formation may be beneficial in maturing the electrical properties of cardiomyocytes. 


\section{Cell cycle arrest}

Mitochondria play integral roles in regulation of the cell cycle [211], while cell cycle state can control mitochondrial behavior [212]. Cardiomyocytes exit the cell cycle shortly after birth coinciding with a period of cardiomyocyte maturation [10]. The shift to oxidative phosphorylation increases ROS production by mitochondria after birth, and ROS scavenging can prolong the proliferative potential by postnatal cardiomyocytes [213]. A positive feedback loop exists between ROS levels, p38 MAPK and connexin 43 (Cx43), with increased ROS promoting expression of p38 MAPK and Cx43, and downregulation of p38 MAPK or mitochondrial Cx43 reducing ROS levels [213]. Increased ROS levels cause oxidative DNA damage that initiates a DNA damage response pathway that leads to cell cycle arrest in cardiomyocytes, while antioxidant treatment prolongs postnatal proliferation capacity [214]. Consumption of milk low in fatty acids also prolongs the postnatal proliferative capacity of cardiomyocytes, while deletion of pyruvate dehydrogenase kinase 4 (PDK4) to enhance glucose utilization and reduce fatty acid oxidation reduces DNA damage and cardiomyocyte size while also increasing proliferation [215]. These results suggest that the change to enteral consumption of breastmilk high in fatty acids both facilitates cardiomyocyte cell cycle arrest and maturation.

Additional regulators can affect both the cell cycle and the metabolic switch in cardiomyocytes. MEIS1, a transcription factor that stimulates cell cycle activity in cardiomyocytes [216], also supports a less mature metabolic phenotype in cardiomyocytes by promoting glycolysis, while MEIS1 siRNA in fetal sheep cardiomyocytes triggers a metabolic switch from glycolysis to oxidative phosphorylation [217]. Deletion of endonuclease G, a mitochondrial enzyme that promotes apoptosis during oxidative stress, increases ROS levels, reduces proliferative capacity of cardiomyocytes in mice, and increases cardiomyocyte size, with cell cycle arrest in the G1 phase [218]. Cardiomyocyte-specific deletion of mitochondrial transcription factor A, Tfam, leads to mitochondrial depolarization which increases ROS production and impairs cardiomyocyte proliferation via activation of the DNA damage response pathway leading to a severe cardiomyopathy that is embryonic lethal in mice [219]. Postnatal inactivation of Tfam at postnatal day 0 (P0) leads to progressive ventricular dysfunction by 6 weeks of age that can be prevented by treating with a ROS scavenger during the first postnatal week but not after the first postnatal week [219]. This suggests that there is a critical window of time in the perinatal transition during which mitochondria regulate both the cell cycle and cardiomyocyte maturation. Targeting this time frame during PSC-CM differentiation may be key to achieving in vitro maturation.

\section{Quiescence versus senescence}

Cell cycle arrest can be reversible (quiescent state) or irreversible (senescent state). Although the majority of adult cardiomyocytes do not re-enter the cell cycle, there is evidence to suggest that they are capable of proliferation under certain conditions [220], suggesting that they reside largely in a quiescent state. Features of quiescent $\left(G_{0}\right)$ cells include low RNA content, lack of proliferation markers, or increased expression of cell cycle inhibitor p27, although characteristics vary by cell type [221] (Fig. 5). In contrast, senescent cells can be arrested at the G1/S or G2/M transition [222] and exhibit elevated ROS and lipofuscin accumulation, increased SA- $\beta$-gal activity, increased expression of cell cycle inhibitors p21 or p16, senescence-associated heterochromatin foci, and have a senescence-associated secretory phenotype (SASP), secreting inflammatory factors such as interleukin-6 (IL-6), IL-8, and matrix metalloproteinases [223] (Fig. 5). Quiescence is considered a state of dormancy that is physiologic, while senescence is characteristic of aging caused by chronic damage to a cell, thus understanding what external stimuli direct cells to one or the other state may important for promote normal development.

Stimuli that promote senescence in non-myocytes include glucose [224], ROS [225], or hyperinsulinemia [226]. Therefore, standard culture conditions with supraphysiologic concentrations of glucose or insulin may promote cellular senescence in PSC-CMs. Extended culture times of PSC-CMs can improve some aspects of maturation [227], but can also increase an aging phenotype, with increased SA- $\beta$-gal activity, increased lipofuscin accumulation, and reduced mitochondrial membrane potential, which can be reversed with treatment with the antioxidant, ascorbic acid [228]. When human PSC-CMs are cultured with young, adult, or aged extracellular matrix proteins from mice, young ECM increases PSC$\mathrm{CM}$ proliferation, adult ECM enhances PSC-CM function, and aged ECM produces an aging phenotype with reduced PSC-CM function and lipofuscin accumulation, increased SA- $\beta$-gal activity, and increased ROS levels [229], suggesting that extracellular factors control transitions between proliferative, quiescent, and senescent phenotypes.

We recently identified that inhibition of mTOR signaling with Torin 1 can promote cardiomyocyte maturation in two-dimensional culture through induction of p53mediated cellular quiescence and suppression of a senescent state [230]. In fibroblasts and other cell types, cell cycle arrest with p53 and mTOR activation induces senescence, while p53 upregulation with mTOR inhibition leads to quiescence [231]. Stimulators of mTOR include glucose and insulin, thus methods that demonstrate enhanced maturation of PSC-CMs with low-glucose, 


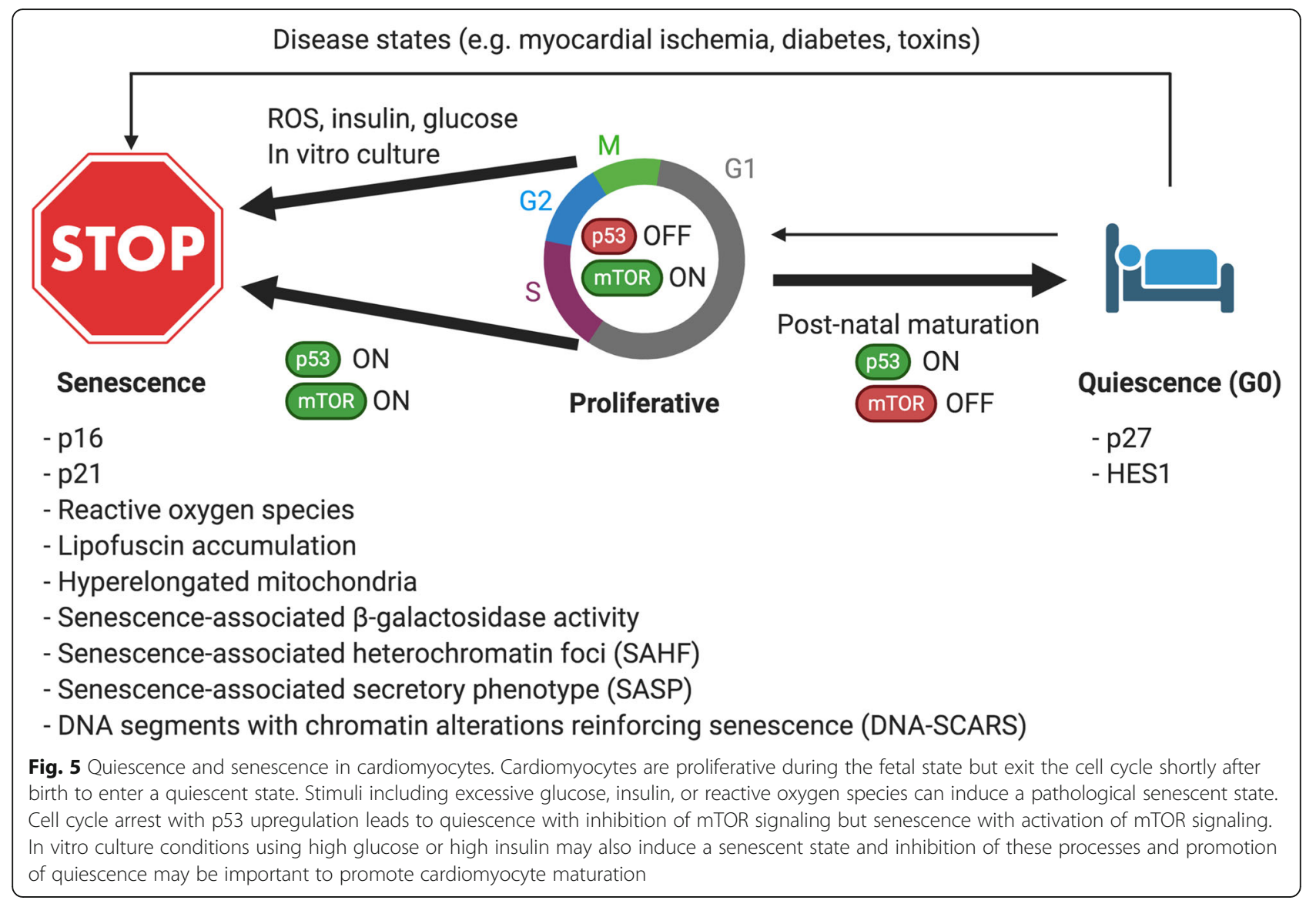

insulin-free media likely also inhibit mTOR activity. These pathways will need to be further tested in threedimensional cultures as a 3D spheroid geometry can inhibit mTOR signaling alone through contact inhibition [232].

Mitochondria maintain quiescence in other cell types by suppressing glycolysis and ROS production [233]. As mentioned above, suppression of ROS may facilitate postnatal cardiomyocyte maturation, which would be supported by quiescence of postnatal cardiomyocytes. Mitochondrial morphology also changes upon transition from a proliferative to a quiescent state in other cell types [234, 235], which likely is accompanied by changes in mitochondrial function. Lysosomes also play an important role in maintaining quiescence depth and regulating mitochondrial degradation [236]. Cell culture conditions may accelerate senescence and prevent maturation; therefore, understanding what conditions promote quiescence rather than senescence may improve PSC-CM maturation.

\section{Epigenetics}

Epigenetic regulation of gene expression via DNA methylation, histone acetylation, or microRNAs plays an important role during cardiomyocyte development [237, 238] and can influence PSC-CM differentiation and maturation [239]. DNA methylation is dynamically regulated throughout cardiomyocyte development and maturation, with increased gene expression of cardiac genes occurring with demethylation during early development and methylation occurring later to silence fetal genes [237]. Interestingly, maternal diets rich in methyl group donors (such as folate) can affect the epigenetic state of the offspring via altered DNA methylation status [240]. Population-based data have associated abnormal maternal DNA methylation with congenital heart disease in offspring, although a causal association between diet and cardiac defects has not been established [240, 241]. Epigenetic priming of differentiating $\mathrm{PSC}-\mathrm{CMs}$ during the mesoderm stage promotes histone H3 lysine 9 acetylation (H3K9ac) of Notch-related genes, accelerating PSC-CM maturation [242]. Increased expression of DNA methyltransferase and increased global methylation during postnatal rat heart development suggests that decreased chromatin accessibility accompanies cardiomyocyte maturation [243]. For instance, reducing histone $\mathrm{H} 3$ acetylation and increasing $\mathrm{H} 3$ lysine 9 trimethylation (H3K9me3) downregulates expression of the fetal isoform of troponin I (ssTNI) [238]. As discussed above, microRNAs can also regulate the epigenetic state by post-transcriptional regulation of gene 
expression [122]. MiRNAs are involved in cardiomyocyte differentiation and maturation [244, 245]. For example, miR-1 can promote cardiomyocyte differentiation [124], while overexpression of miR-200c impairs differentiation and maturation of PSC-CMs [246]. Mitochondrial miRNAs (mitomiRs) can also regulate metabolism, energy status, and mitochondrial dynamics [247, 248].

Mitochondria play central roles in regulating the epigenetic state by producing metabolites such as acetylCoA and $\alpha$-ketoglutarate $(\alpha-K G)$ that can regulate histone acetylation or DNA methylation $[249,250]$ and has been reviewed previously [251, 252]. Bromodomaincontaining protein 4 (BRD4) is an epigenetic reader protein that recognizes acetylated chromatin sites that was recently identified to promote mitochondrial homeostasis in cardiomyocytes through GATA4-mediated upregulation of PGC- $1 \alpha$ and PGC-1 $\beta$ [253, 254]. The sirtuin family of class III histone deacetylases can be activated by AMPK during low energy states to upregulate genes associated with mitochondrial biogenesis and can protect against damage from oxidative stress [255].

\section{Mitochondrial regulation of electrophysiological maturation}

Automaticity of immature PSC-CMs is a major barrier to clinical translation due to the increased risk of ventricular arrhythmias seen when PSC-CMs are injected into large animal models of myocardial ischemia [256258]. Imbalance of the inward rectifier $\mathrm{K}+$ current $\left(I_{\mathrm{k} 1}\right)$ due to reduced expression of KCNJ2 and the funny current $\left(I_{\mathrm{f}}\right)$ due to a relative increase in the hyperpolarization-activated cyclic nucleotide-gated $(\mathrm{HCN})$ ion channels may be responsible for automaticity of PSC-CMs [259, 260]. Time-dependent changes in expression of miR-1 may be important in regulating electrophysiological maturation, as miR-1 levels are normally rise after birth, but premature overexpression of miR-1 leads to underdevelopment of the cardiac conduction system [261]. The risk of arrhythmias decreases over the first few weeks after cell delivery as PSC-CMs undergo further maturation in vivo, although the mechanisms for this remain unclear [256-258]. It is possible that changes in mitochondrial dynamics regulate this transition following exposure to the in vivo environment. Oscillations in the redox state of a cell due to dynamic nutrient metabolism can affect membrane current in cardiomyocytes [262, 263]. Neonatal rat ventricular cardiomyocytes reprogrammed into cardiac pacemaker cells with TBX18 transduction displayed automaticity, exhibited a lower metabolic demand, had smaller and more globular mitochondria, and had increased mitochondrial fission due to Opal downregulation compared to ventricular cardiomyocytes [264]. In addition, deletion of cyclophilin D leading to closure of the MPTP reduces the risk of ventricular arrhythmias [265]. Mutations in hydratase subunit A (HADHA) can cause sudden infant death syndrome due to cardiac arrhythmias after initiation of enteral feeds; PSC-CMs with deletion of HADHA have an immature cardiomyocyte phenotype, fragmented mitochondria with accumulation of longchain fatty acids, and an increase in action potential duration although no change in resting membrane potential [266]. Elevated ROS can lead to mitochondrial membrane depolarization, leading to arrhythmia risk after ischemic injury [267]. Not only can mitochondria affect electrical maturation, electrical stimulation of neonatal rat ventricular cardiomyocytes can also regulate mitochondrial function via upregulation of nuclear respiratory factor 1 (NRF-1), cytochrome oxidase, and carnitine palmitoyltransferase I (CPT-I) [268].

\section{Connexin 43}

Connexin 43 (Cx43; encoded by GJA1) is best known as a gap junction protein that permits intercellular communication between cardiomyocytes; however, it also plays an important role during heart development [269, 270]. Global Cx43 deletion leads to right ventricular outflow tract obstruction and increased arrhythmia risk [271, 272], while cardiomyocyte-specific deletion of Cx43 leads to myocardial hypertrophy, prolongation of the QRS interval, ventricular tachyarrhythmias, and juvenile death [270, 273]. Cx43 expression is decreased in heart failure [274], while restoring Cx43 expression following myocardial infarction reduces the risk of ventricular tachycardia in animal models [275]. While the heart has high expression of the full-length, $43 \mathrm{kDa}$ isoform of Cx43, it is actually the smaller, $20 \mathrm{kDa}$ isoform (GJA1$20 \mathrm{k}$ ) formed by alternative translation that is the most abundant isoform in the heart [276]. Poorly trafficked full-length Cx43 is degraded without GJA1-20k, leading to sudden cardiac death despite normal contractile function in mice [277]. GJA1-20k also associates with mitochondria to stimulate mitochondrial biogenesis via upregulation of PGC-1 $\alpha$ and support a quiescent state with reduced ROS production [278]. In PSC-CMs, overexpression of $\mathrm{Cx} 43$ improves intercellular communication and improves function of the voltage-gated $\mathrm{Na}+$ channels $\left(\mathrm{Na}_{\mathrm{v}} 1.5\right)$ to increase the action potential upstroke velocity and $I_{\mathrm{Na}}$ current [279].

Nutrient availability can affect $\mathrm{Cx} 43$ expression, and Cx43 expression can affect both mitochondrial function and senescence. Hyperglycemic conditions downregulate expression of $\mathrm{Cx} 43$ while activation of AMPK increases Cx43 expression [280]. Inhibition of mTOR signaling increases expression of GJA1-20k via inhibition of capdependent protein translation to facilitate trafficking of the full-length isoform to the cell membrane [276]. GJA1-20k overexpression increases formation of $\mathrm{Cx} 43$ 


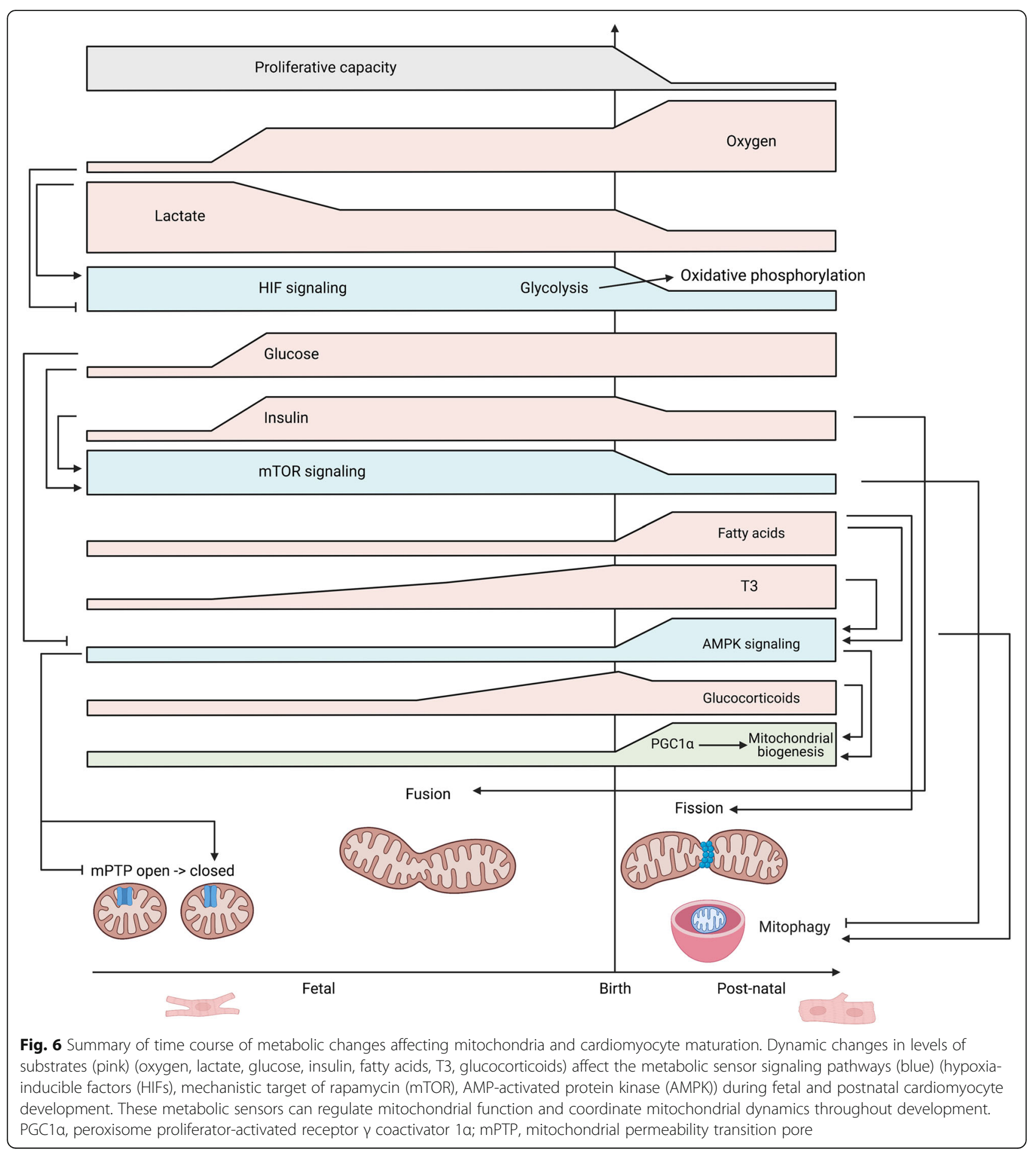

gap junctions, enhances mitochondrial biogenesis, and reduces ROS levels despite increased mitochondrial membrane potential and increased oxygen consumption in angiotensin II-induced cardiomyocyte hypertrophy [281]. Mitochondrial Cx43 can inhibit mPTP opening, which reduces ROS release [282]. GJA1-20k has a protective effect during oxidative stress to limit mitochondrial fragmentation in non-myocytes [283], while excessive oxidative stress and excessive mitochondrial fission can lead to degradation of $\mathrm{Cx} 43$ in cardiomyocytes [284].

Reduced Cx43 is considered a marker for senescence in fibroblasts [285], glomerular mesangial cells [286], and hematopoietic stem cells (HSCs) [287], although upregulation of $\mathrm{Cx} 43$ increases senescence of chondrocytes [288]. Cx43 prevents senescence in HSCs by forming 
gap junctions between HSCs and adjacent bone marrow stromal cells to transfer ROS and prevent redox damage to the HSCs [287]. Whether a similar bodyguard effect occurs between cardiomyocytes and other cell types is unclear but may also explain how ROS levels are decreased in cardiomyocytes with high $\mathrm{Cx} 43$ expression despite increased oxygen consumption rate.

\section{Resting membrane potential}

Mitochondrial dysfunction can also impair activity of the inward rectifying $\mathrm{K}^{+}$ion channel, Kir2.1 (encoded by KCNJ2). Kir2.1 is largely responsible for the $I_{\mathrm{k} 1}$ current which maintains the resting membrane potential of cardiomyocytes [289]. Skeletal myoblasts with depletion of mitochondrial DNA or inhibition of mitochondrial complex III with antimycin A had reduced expression of Kir2.1 leading to membrane depolarization, suggesting that impaired oxidative phosphorylation can have direct adverse effects on resting membrane potential [290]. AMPK activation downregulates Kir2.1 [291], and we recently found that sustained activation can enhance maturation of contractile and metabolic features of PSCCMs but also reduces expression of KCNJ2 [292]. In contrast, in neurons, mTOR signaling increases expression of HCN channels [293]. Dysregulation of AMPK and mTOR signaling may affect expression levels of Kir2.1 and HCN4 in cardiomyocytes, leading to cardiomyocyte membrane depolarization.

\section{Summary}

Metabolic signals can alter mitochondrial dynamics and function, and this may precede downstream regulation of cardiomyocyte maturation. Crosstalk between key nutrient sensing systems including mTOR and AMPK can control mitochondrial behavior leading to alterations in ROS levels, cell cycle arrest, and epigenetic changes. Mimicking key developmental transitions that directly involve mitochondria such as at $\sim$ E9.5 in mice with closure of the MPTP or at birth with transition to enteral nutrition may be critical to enhance PSC-CM maturation in vitro. Interplay between multiple metabolic factors affects mitochondrial dynamics and cardiomyocyte maturation in a time-dependent manner throughout development (Fig. 6). Mitochondria may be the conductors that drive cardiomyocyte maturation by responding to nutrient signals, dynamically altering respiratory capacity and ROS production, and initiating transcriptional and epigenetic changes guiding cardiomyocyte maturation.

\section{Abbreviations}

AMP: Adenosine monophosphate; AMPK: AMP-activated protein kinase: ATP: Adenosine triphosphate; ATRA: All-trans retinoic acid; BCAA: Branched chain amino acids; CAMKIl: $\mathrm{Ca}^{2+} /$ calmodulin-dependent protein kinase II; Cx43: Connexin 43; DMEM: Dulbecco's modified Eagle's medium;
ERR: Estrogen-related receptor; ESC: Embryonic stem cell; FDG: Fluorodeoxyglucose; HADHA: Hydratase subunit A; HIF: Hypoxiainducible factor; IGF1: Insulin-like growth factor 1; IMM: Inner mitochondrial membrane; KLF15: Krüppel-like factor 15; LDH: Lactate dehydrogenase; LXRa: Liver X receptor a; MAO-A: Monoamine oxidase-A; MHCa: Myosin heavy chain a; miRNA: MicroRNA; MLC2v: Myosin light chain 2V; mPTP: Mitochondrial permeability transition pore; mTOR: Mechanistic target of rapamycin; mTORC: mTOR complex; NRG1: Neuregulin-1; O-GIcNAc: Olinked N-acetylglucosamine; OMM: Outer mitochondrial membrane; P70S6K: p70 ribosomal protein S6 kinase activity; PGC-1a: PPARY coactivator 1a; PPARY: Peroxisome proliferator-activated receptor $\gamma_{i}$

PI3K: Phosphoinositide 3-kinase; PSC: Pluripotent stem cells; PSCCMs: Pluripotent stem cell-derived cardiomyocytes; RARE: Retinoic acid response element; ROS: Reactive oxygen species; RPMI: Roswell Park Memorial Institute 1640 medium; SA- $\beta$-gal: Senescence-associated- $\beta$ galactosidase; SASP: Senescence-associated secretory phenotype; SERCA: Sarco-endoplasmic reticulum calcium-ATPase; TNNT2: Cardiac troponin $\mathrm{T}$

\section{Acknowledgements}

Figures were created with BioRender.com.

\section{Authors' contributions}

J.C.G wrote the initial draft of the manuscript and designed the figures. R.T.L. edited the manuscript. Both authors reviewed and approved the final manuscript.

\section{Funding}

This work was supported by the National Institutes of Health [K08 HL150335 to JCG, HL151684 and HL137710 to RTL].

\section{Availability of data and materials}

Not applicable.

\section{Declarations}

Ethics approval and consent to participate

Not applicable.

\section{Consent for publication}

Not applicable.

\section{Competing interests}

RTL is a co-founder, scientific advisory board member, and private equity holder of Elevian, Inc. Elevian also provides sponsored research support to the Lee Laboratory. RTL is a member of the scientific advisory board of Novo Biosciences.

\section{Author details}

'Department of Stem Cell and Regenerative Biology and the Harvard Stem Cell Institute, Harvard University, 7 Divinity Ave, Cambridge, MA 02138, USA. ${ }^{2}$ Department of Cardiology, Boston Children's Hospital, 300 Longwood Ave, Boston, MA 02115, USA. ${ }^{3}$ Division of Cardiovascular Medicine, Department of Medicine, Brigham and Women's Hospital and Harvard Medical School, 75 Francis St, Boston, MA 02115, USA.

Received: 7 January 2021 Accepted: 28 February 2021

Published online: 12 March 2021

\section{References}

1. Lian X, Zhang J, Azarin SM, Zhu K, Hazeltine LB, Bao X, et al. Directed cardiomyocyte differentiation from human pluripotent stem cells by modulating Wnt/beta-catenin signaling under fully defined conditions. Nat Protoc. 2013;8(1):162-75. https://doi.org/10.1038/nprot.2012.150.

2. Karbassi E, Fenix A, Marchiano S, Muraoka N, Nakamura K, Yang X, et al. Cardiomyocyte maturation: advances in knowledge and implications for regenerative medicine. Nat Rev Cardiol. 2020;17(6):341-59. https://doi.org/1 0.1038/s41569-019-0331-.

3. Hu D, Linders A, Yamak A, Correia C, Kijlstra JD, Garakani A, et al. Metabolic maturation of human pluripotent stem cell-derived cardiomyocytes by 
inhibition of HIF1alpha and LDHA. Circ Res. 2018;123(9):1066-79. https://doi. org/10.1161/CIRCRESAHA.118.313249.

4. Yang X, Rodriguez ML, Leonard A, Sun L, Fischer KA, Wang Y, et al. Fatty acids enhance the maturation of cardiomyocytes derived from human pluripotent stem cells. Stem Cell Reports. 2019;13(4):657-68. https:/doi. org/10.1016/.jstemcr.2019.08.013.

5. Yang X, Rodriguez M, Pabon L, Fischer KA, Reinecke H, Regnier M, et al. Triiodo-l-thyronine promotes the maturation of human cardiomyocytesderived from induced pluripotent stem cells. J Mol Cell Cardiol. 2014;72: 296-304. https://doi.org/10.1016/j.yjmcc.2014.04.005.

6. Mills RJ, Titmarsh DM, Koenig X, Parker BL, Ryall JG, Quaife-Ryan GA, et al. Functional screening in human cardiac organoids reveals a metabolic mechanism for cardiomyocyte cell cycle arrest. Proc Natl Acad Sci U S A. 2017;114(40):E8372-E81. https://doi.org/10.1073/pnas.1707316114.

7. Feyen DAM, McKeithan WL, Bruyneel AAN, Spiering S, Hormann L, Ulmer B, et al. Metabolic maturation media improve physiological function of human iPSC-derived cardiomyocytes. Cell Rep. 2020;32(3):107925. https://doi.org/1 0.1016/j.celrep.2020.107925

8. Piquereau J, Ventura-Clapier R. Maturation of cardiac energy metabolism during perinatal development. Front Physiol. 2018;9:959. https://doi.org/1 0.3389/fphys.2018.00959.

9. Slaats RH, Schwach V, Passier R. Metabolic environment in vivo as a blueprint for differentiation and maturation of human stem cell-derived cardiomyocytes. Biochim Biophys Acta Mol Basis Dis. 2020;1866(10):165881. https://doi.org/10.1016/j.bbadis.2020.165881.

10. Yuan X, Braun T. Multimodal regulation of cardiac myocyte proliferation. Circ Res. 2017;121(3):293-309. https://doi.org/10.1161/CIRCRESAHA.117.3 08428.

11. Siddiqi S, Sussman MA. The heart: mostly postmitotic or mostly premitotic? Myocyte cell cycle, senescence, and quiescence. Can J Cardiol. 2014;30(11): 1270-8. https://doi.org/10.1016/j.cjca.2014.08.014.

12. Vega RB, Horton JL, Kelly DP. Maintaining ancient organelles: mitochondrial biogenesis and maturation. Circ Res. 2015;116(11):1820-34. https://doi.org/1 0.1161/CIRCRESAHA.116.305420

13. Marchiano S, Bertero A, Murry CE. Learn from your elders: developmental biology lessons to guide maturation of stem cell-derived cardiomyocytes. Pediatr Cardiol. 2019;40(7):1367-87. https://doi.org/10.1007/s00246-019-021 65-5.

14. Yang X, Pabon L, Murry CE. Engineering adolescence: maturation of human pluripotent stem cell-derived cardiomyocytes. Circ Res. 2014;114(3):511-23. https://doi.org/10.1161/CIRCRESAHA.114.300558.

15. Dai DF, Danoviz ME, Wiczer B, Laflamme MA, Tian R. Mitochondrial maturation in human pluripotent stem cell derived cardiomyocytes. Stem Cells Int. 2017;2017:5153625. https://doi.org/10.1155/2017/5153625.

16. Efeyan A, Comb WC, Sabatini DM. Nutrient-sensing mechanisms and pathways. Nature. 2015;517(7534):302-10. https://doi.org/10.1038/nature141 90.

17. Miyamoto T, Wright G, Amrein H. Nutrient sensors. Curr Biol. 2013;23(9): R369-73. https://doi.org/10.1016/j.cub.2013.04.002.

18. Cerychova R, Pavlinkova G. HIF-1, metabolism, and diabetes in the embryonic and adult heart. Front Endocrinol (Lausanne). 2018;9:460. https:// doi.org/10.3389/fendo.2018.00460.

19. Kubli DA, Gustafsson AB. Cardiomyocyte health: adapting to metabolic changes through autophagy. Trends Endocrinol Metab. 2014;25(3):156-64. https://doi.org/10.1016/.jtem.2013.11.004.

20. Hardie DG, Ross FA, Hawley SA. AMPK: a nutrient and energy sensor that maintains energy homeostasis. Nat Rev Mol Cell Biol. 2012;13(4):251-62. https://doi.org/10.1038/nrm3311.

21. Howell JJ, Manning BD. mTOR couples cellular nutrient sensing to organismal metabolic homeostasis. Trends Endocrinol Metab. 2011;22(3):94102. https://doi.org/10.1016/j.tem.2010.12.003.

22. Alam S, Abdullah CS, Aishwarya R, Morshed M, Bhuiyan MS. Molecular perspectives of mitochondrial adaptations and their role in cardiac proteostasis. Front Physiol. 2020;11:1054. https://doi.org/10.3389/fphys.2020. 01054.

23. Land SC. Tee AR. Hypoxia-inducible factor 1alpha is regulated by the mammalian target of rapamycin (mTOR) via an mTOR signaling motif. J Biol Chem. 2007;282(28):20534-43. https://doi.org/10.1074/jbc.M611782200.

24. Thomas LW, Ashcroft M. Exploring the molecular interface between hypoxia-inducible factor signalling and mitochondria. Cell Mol Life Sci. 2019: 76(9):1759-77. https://doi.org/10.1007/s00018-019-03039-y.
25. Tomasetti M, Neuzil J, Dong L. MicroRNAs as regulators of mitochondria function: role in cancer suppression. Biochim Biophys Acta. 2014;1840(4): 1441-53. https://doi.org/10.1016/j.bbagen.2013.09.002.

26. Sciarretta S, Forte M, Frati G, Sadoshima J. New insights into the role of mTOR signaling in the cardiovascular system. Circ Res. 2018;122(3):489-505. https://doi.org/10.1161/CIRCRESAHA.117.311147.

27. Abumrad NA, Goldberg IJ. CD36 actions in the heart: lipids, calcium, inflammation, repair and more? Biochim Biophys Acta. 2016;1861(10):14429. https://doi.org/10.1016/j.bbalip.2016.03.015.

28. Batho CAP, Mills RJ, Hudson JE. Metabolic regulation of human pluripotent stem cell-derived cardiomyocyte maturation. Curr Cardiol Rep. 2020;22(8):73. https://doi.org/10.1007/s11886-020-01303-3.

29. Patterson AJ, Zhang L. Hypoxia and fetal heart development. Curr Mol Med. 2010;10(7):653-66. https://doi.org/10.2174/156652410792630643.

30. Salceda S, Caro J. Hypoxia-inducible factor lalpha (HIF-1alpha) protein is rapidly degraded by the ubiquitin-proteasome system under normoxic conditions. Its stabilization by hypoxia depends on redox-induced changes. J Biol Chem. 1997;272(36):22642-7. https://doi.org/10.1074/jbc.272.36.22642.

31. Hu CJ, Wang LY, Chodosh LA, Keith B, Simon MC. Differential roles of hypoxia-inducible factor 1alpha (HIF-1alpha) and HIF-2alpha in hypoxic gene regulation. Mol Cell Biol. 2003;23(24):9361-74. https://doi.org/10.1128/ mcb.23.24.9361-9374.2003.

32. Bozzetti P, Buscaglia M, Cetin I, Marconi AM, Nicolini U, Pardi G, et al. Respiratory gases, acid-base balance and lactate concentrations of the midterm human fetus. Biol Neonate. 1987;52(4):188-97. https://doi.org/10.11 $59 / 000242709$

33. Ma LN, Huang XB, Muyayalo KP, Mor G, Liao AH. Lactic acid: a novel signaling molecule in early pregnancy? Front Immunol. 2020;11:279. https:// doi.org/10.3389/fimmu.2020.00279.

34. Marconi AM, Cetin I, Ferrazzi E, Ferrari MM, Pardi G, Battaglia FC. Lactate metabolism in normal and growth-retarded human fetuses. Pediatr Res. 1990;28(6):652-6. https://doi.org/10.1203/00006450-199012000-00022.

35. Kozlov AM, Lone A, Betts DH, Cumming RC. Lactate preconditioning promotes a HIF-1alpha-mediated metabolic shift from OXPHOS to glycolysis in normal human diploid fibroblasts. Sci Rep. 2020;10(1):8388. https://doi. org/10.1038/s41598-020-65193-9.

36. Lu H, Forbes RA, Verma A. Hypoxia-inducible factor 1 activation by aerobic glycolysis implicates the Warburg effect in carcinogenesis. J Biol Chem. 2002;277(26):23111-5. https://doi.org/10.1074/jbc.M202487200.

37. Iyer NV, Kotch LE, Agani F, Leung SW, Laughner E, Wenger RH, et al. Cellular and developmental control of $\mathrm{O} 2$ homeostasis by hypoxia-inducible factor 1 alpha. Genes Dev. 1998;12(2):149-62. https://doi.org/10.1101/gad.12.2.149.

38. Kudova J, Prochazkova J, Vasicek O, Perecko T, Sedlackova M, Pesl M, et al. HIF1 alpha deficiency attenuates the cardiomyogenesis of mouse embryonic stem cells. PLoS One. 2016;11(6):e0158358. https://doi.org/10.1371/journal.pone.0158358.

39. Gentillon C, Li D, Duan M, Yu WM, Preininger MK, Jha R, et al. Targeting HIFlalpha in combination with PPARalpha activation and postnatal factors promotes the metabolic maturation of human induced pluripotent stem cell-derived cardiomyocytes. J Mol Cell Cardiol. 2019;132:120-35. https://doi. org/10.1016/j.yjmcc.2019.05.003.

40. Moreno-Manzano V, Rodriguez-Jimenez FJ, Acena-Bonilla JL, Fustero-Lardies S, Erceg S, Dopazo J, et al. FM19G11, a new hypoxia-inducible factor (HIF) modulator, affects stem cell differentiation status. J Biol Chem. 2010;285(2): 1333-42. https://doi.org/10.1074/jbc.M109.008326.

41. Darmaun D. Role of nutrients in the regulation of in vivo protein metabolism in humans. Acta Paediatr Suppl. 1999;88(433):92-4. https://doi. org/10.1111/j.1651-2227.1999.tb14412.x

42. Chung S, Dzeja PP, Faustino RS, Perez-Terzic C, Behfar A, Terzic A. Mitochondrial oxidative metabolism is required for the cardiac differentiation of stem cells. Nat Clin Pract Cardiovasc Med. 2007;4(Suppl 1): S60-7. https://doi.org/10.1038/ncpcardio0766.

43. Malandraki-Miller S, Lopez CA, Al-Siddiqi H, Carr CA. Changing metabolism in differentiating cardiac progenitor cells-can stem cells become metabolically flexible cardiomyocytes? Front Cardiovasc Med. 2018;5:119. https://doi.org/10.3389/fcrm.2018.00119.

44. van Herwijnen MJC, Driedonks TAP, Snoek BL, Kroon AMT, Kleinjan M, Jorritsma R, et al. Abundantly present mirnas in milk-derived extracellular vesicles are conserved between mammals. Front Nutr. 2018;5:81. https://doi. org/10.3389/fnut.2018.00081.

45. Kuppusamy KT, Jones DC, Sperber H, Madan A, Fischer KA, Rodriquez ML, et al. Let-7 family of microRNA is required for maturation and adult-like 
metabolism in stem cell-derived cardiomyocytes. Proc Natl Acad Sci U S A 2015;112(21):E2785-94. https://doi.org/10.1073/pnas.1424042112.

46. Holme AM, Roland MC, Lorentzen B, Michelsen TM, Henriksen T. Placental glucose transfer: a human in vivo study. PLoS One. 2015;10(2):e0117084. https://doi.org/10.1371/journal.pone.0117084.

47. Thompson-Branch A, Havranek T. Neonatal Hypoglycemia. Pediatr Rev. 2017; 38(4):147-57. https://doi.org/10.1542/pir.2016-0063.

48. Nakano H, Minami I, Braas D, Pappoe H, Wu X, Sagadevan A, et al. Glucose inhibits cardiac muscle maturation through nucleotide biosynthesis. Elife. 2017;6 https://doi.org/10.7554/eLife.29330.

49. Basu M, Garg V. Maternal hyperglycemia and fetal cardiac development: clinical impact and underlying mechanisms. Birth Defects Res. 2018;110(20): 1504-16. https://doi.org/10.1002/bdr2.1435.

50. Nose N, Werner RA, Ueda Y, Gunther K, Lapa C, Javadi MS, et al. Metabolic substrate shift in human induced pluripotent stem cells during cardiac differentiation: functional assessment using in vitro radionuclide uptake assay. Int J Cardiol. 2018;269:229-34. https://doi.org/10.1016/j.jicard.2018.06.089.

51. Yang P, Chen X, Kaushal S, Reece EA, Yang P. High glucose suppresses embryonic stem cell differentiation into cardiomyocytes: high glucose inhibits ES cell cardiogenesis. Stem Cell Res Ther. 2016;7(1):187. https://doi. org/10.1186/s13287-016-0446-5

52. Siziba LP, Lorenz L, Stahl B, Mank M, Marosvolgyi T, Decsi T, et al. Changes in human milk fatty acid composition during lactation: the UIm SPATZ Health Study. Nutrients. 2019;11(12) https://doi.org/10.3390/nu11122842.

53. Makinde AO, Kantor PF, Lopaschuk GD. Maturation of fatty acid and carbohydrate metabolism in the newborn heart. Mol Cell Biochem. 1998; 188(1-2):49-56.

54. Horikoshi Y, Yan Y, Terashvili M, Wells C, Horikoshi H, Fujita S, et al. Fatty acid-treated induced pluripotent stem cell-derived human cardiomyocytes exhibit adult cardiomyocyte-like energy metabolism phenotypes. Cells. 2019;8(9) https://doi.org/10.3390/cells8091095.

55. Correia C, Koshkin A, Duarte P, Hu D, Teixeira A, Domian I, et al. Distinct carbon sources affect structural and functional maturation of cardiomyocytes derived from human pluripotent stem cells. Sci Rep. 2017; 7(1):8590. https://doi.org/10.1038/s41598-017-08713-4.

56. Ye Z, Wang S, Zhang C, Zhao Y. Coordinated modulation of energy metabolism and inflammation by branched-chain amino acids and fatty acids. Front Endocrinol (Lausanne). 2020;11:617. https://doi.org/10.3389/ fendo.2020.00617.

57. Zhang X, Lin Q, Chen J, Wei T, Li C, Zhao L, et al. High glucose-induced cardiomyocyte death may be linked to unbalanced branched-chain amino acids and energy metabolism. Molecules. 2018;23(4) https://doi.org/10.3390/ molecules23040807.

58. Shao D, Villet O, Zhang Z, Choi SW, Yan J, Ritterhoff J, et al. Glucose promotes cell growth by suppressing branched-chain amino acid degradation. Nat Commun. 2018;9(1):2935. https://doi.org/10.1038/s41467018-05362-7.

59. D'Antona G, Ragni M, Cardile A, Tedesco L, Dossena M, Bruttini F, et al. Branched-chain amino acid supplementation promotes survival and supports cardiac and skeletal muscle mitochondrial biogenesis in middleaged mice. Cell Metab. 2010;12(4):362-72. https://doi.org/10.1016/j.cmet.201 0.08.016.

60. Tedesco L, Rossi F, Ragni M, Ruocco C, Brunetti D, Carruba MO, et al. A special amino-acid formula tailored to boosting cell respiration prevents mitochondrial dysfunction and oxidative stress caused by doxorubicin in mouse cardiomyocytes. Nutrients. 2020;12(2) https://doi.org/10.3390/nu1202 0282.

61. Li P, Cavallero S, Gu Y, Chen TH, Hughes J, Hassan AB, et al. IGF signaling directs ventricular cardiomyocyte proliferation during embryonic heart development. Development. 2011;138(9):1795-805. https://doi.org/10.1242/ dev.054338.

62. Freund C, Ward-van Oostwaard D, Monshouwer-Kloots J, van den Brink S, van Rooijen M, Xu X, et al. Insulin redirects differentiation from cardiogenic mesoderm and endoderm to neuroectoderm in differentiating human embryonic stem cells. Stem Cells. 2008;26(3):724-33. https://doi.org/10.1634/ stemcells.2007-0617.

63. Lian X, Zhang J, Zhu K, Kamp TJ, Palecek SP. Insulin inhibits cardiac mesoderm, not mesendoderm, formation during cardiac differentiation of human pluripotent stem cells and modulation of canonical Wnt signaling can rescue this inhibition. Stem Cells. 2013;31(3):447-57. https://doi.org/10.1 002/stem.1289.
64. Engels MC, Rajarajan K, Feistritzer R, Sharma A, Nielsen UB, Schalij MJ, et al. Insulin-like growth factor promotes cardiac lineage induction in vitro by selective expansion of early mesoderm. Stem Cells. 2014;32(6):1493-502. https://doi.org/10.1002/stem.1660.

65. McDevitt TC, Laflamme MA, Murry CE. Proliferation of cardiomyocytes derived from human embryonic stem cells is mediated via the IGF/PI 3kinase/Akt signaling pathway. J Mol Cell Cardiol. 2005;39(6):865-73. https:// doi.org/10.1016/j.yjmcc.2005.09.007.

66. Rupert CE, Coulombe KLK. IGF1 and NRG1 enhance proliferation, metabolic maturity, and the force-frequency response in hESC-derived engineered cardiac tissues. Stem Cells Int. 2017;2017:7648409. https://doi.org/10.1155/2 017/7648409.

67. Sharma S, Guthrie PH, Chan SS, Haq S, Taegtmeyer H. Glucose phosphorylation is required for insulin-dependent $\mathrm{mTOR}$ signalling in the heart. Cardiovasc Res. 2007;76(1):71-80. https://doi.org/10.1016/j.cardiores.2 007.05.004.

68. Yao H, Han X, Han X. The cardioprotection of the insulin-mediated PI3K/Akt/ mTOR signaling pathway. Am J Cardiovasc Drugs. 2014;14(6):433-42. https://doi.org/10.1007/s40256-014-0089-9.

69. Parra V, Verdejo HE, Iglewski M, Del Campo A, Troncoso R, Jones D, et al. Insulin stimulates mitochondrial fusion and function in cardiomyocytes via the Akt-mTOR-NFkappaB-Opa-1 signaling pathway. Diabetes. 2014;63(1):7588. https://doi.org/10.2337/db13-0340.

70. Thorpe-Beeston JG, Nicolaides KH, Felton CV, Butler J, McGregor AM. Maturation of the secretion of thyroid hormone and thyroid-stimulating hormone in the fetus. N Engl J Med. 1991;324(8):532-6. https://doi.org/10.1 056/NEJM199102213240805.

71. Wedrychowicz A, Furtak A, Prosniak A, Zuberek M, Szczerkowska M, Pacut P, et al. Extrathyroidal congenital defects in children with congenital hypothyroidism - observations from a single paediatric centre in Central Europe with a review of literature. Pediatr Endocrinol Diabetes Metab. 2019; 25(3):114-21. https://doi.org/10.5114/pedm.2019.87178.

72. Chattergoon NN, Giraud GD, Thornburg KL. Thyroid hormone inhibits proliferation of fetal cardiac myocytes in vitro. J Endocrinol. 2007;192(2):R18. https://doi.org/10.1677/JOE-06-0114.

73. Chattergoon NN, Giraud GD, Louey S, Stork P, Fowden AL, Thornburg KL. Thyroid hormone drives fetal cardiomyocyte maturation. FASEB J. 2012; 26(1):397-408. https://doi.org/10.1096/fj.10-179895.

74. Chattergoon NN, Louey S, Scanlan T, Lindgren I, Giraud GD, Thornburg KL. Thyroid hormone receptor function in maturing ovine cardiomyocytes. Physiol. 2019;597(8):2163-76. https://doi.org/10.1113/JP276874.

75. Gloss B, Trost S, Bluhm W, Swanson E, Clark R, Winkfein R, et al. Cardiac ion channel expression and contractile function in mice with deletion of thyroid hormone receptor alpha or beta. Endocrinology. 2001;142(2):544-50. https://doi.org/10.1210/endo.142.2.7935.

76. Takano AP, Diniz GP, Barreto-Chaves ML. AMPK signaling pathway is rapidly activated by $\mathrm{T3}$ and regulates the cardiomyocyte growth. Mol Cell Endocrinol. 2013;376(1-2):43-50. https://doi.org/10.1016/..mce.2013.05.024.

77. Zeng B, Liu L, Liao X, Zhang C, Ruan H. Thyroid hormone protects cardiomyocytes from $\mathrm{H}_{2} \mathrm{O} 2$-induced oxidative stress via the PI3K-AKT signaling pathway. Exp Cell Res. 2019;380(2):205-15. https://doi.org/10.1016/ j.yexcr.2019.05.003.

78. Parikh SS, Blackwell DJ, Gomez-Hurtado N, Frisk M, Wang L, Kim K, et al. Thyroid and glucocorticoid hormones promote functional T-tubule development in human-induced pluripotent stem cell-derived cardiomyocytes. Circ Res. 2017;121(12):1323-30. https://doi.org/10.1161/ CIRCRESAHA.117.311920.

79. Lin B, Lin X, Stachel M, Wang E, Luo Y, Lader J, et al. Culture in glucosedepleted medium supplemented with fatty acid and 3,3'5-triiodo-thyronine facilitates purification and maturation of human pluripotent stem cell-derived cardiomyocytes. Front Endocrinol (Lausanne). 2017;8:253. https://doi.org/10.3389/fendo.2017.00253.

80. Manabe M, Nishida T, Imai T, Kusaka T, Kawada K, Okada H, et al. Cortisol levels in umbilical vein and umbilical artery with or without antenatal corticosteroids. Pediatr Int. 2005;47(1):60-3. https://doi.org/10.1111/j.1442-200x.2004.02002.x.

81. Pinto RA, Arredondo SM, Bono MR, Gaggero AA, Diaz PV. T helper 1/T helper 2 cytokine imbalance in respiratory syncytial virus infection is associated with increased endogenous plasma cortisol. Pediatrics. 2006; 117(5):e878-86. https://doi.org/10.1542/peds.2005-2119.

82. Rog-Zielinska EA, Thomson A, Kenyon CJ, Brownstein DG, Moran CM, Szumska D, et al. Glucocorticoid receptor is required for foetal heart 
maturation. Hum Mol Genet. 2013;22(16):3269-82. https://doi.org/10.1093/ hmg/ddt182.

83. Kim MY, Eiby YA, Lumbers ER, Wright LL, Gibson KJ, Barnett AC, et al. Effects of glucocorticoid exposure on growth and structural maturation of the heart of the preterm piglet. PLoS One. 2014;9(3):e93407. https://doi.org/1 0.1371/journal.pone.0093407.

84. Kosmidis G, Bellin M, Ribeiro MC, van Meer B, Ward-van Oostwaard D, Passier $\mathrm{R}$, et al. Altered calcium handling and increased contraction force in human embryonic stem cell derived cardiomyocytes following short term dexamethasone exposure. Biochem Biophys Res Commun. 2015;467(4):9981005. https://doi.org/10.1016/j.bbrc.2015.10.026.

85. Huang CY, Peres Moreno Maia-Joca R, Ong CS, Wilson I, DiSilvestre D, Tomaselli GF, et al. Enhancement of human iPSC-derived cardiomyocyte maturation by chemical conditioning in a 3D environment. J Mol Cell Cardiol. 2020;138:1-11. https://doi.org/10.1016/j.yjmcc.2019.10.001.

86. Oakley RH, Cidlowski JA. Glucocorticoid signaling in the heart: a cardiomyocyte perspective. J Steroid Biochem Mol Biol. 2015;153:27-34. https://doi.org/10.1016/j.jsbmb.2015.03.009.

87. Wei L, MacDonald TM, Walker BR. Taking glucocorticoids by prescription is associated with subsequent cardiovascular disease. Ann Intern Med. 2004; 141(10):764-70. https://doi.org/10.7326/0003-4819-141-10-200411160-00007.

88. Rog-Zielinska EA, Craig MA, Manning JR, Richardson RV, Gowans GJ, Dunbar DR, et al. Glucocorticoids promote structural and functional maturation of foetal cardiomyocytes: a role for PGC-1alpha. Cell Death Differ. 2015;22(7): 1106-16. https://doi.org/10.1038/cdd.2014.181.

89. Liu Y, Bai H, Guo F, Thai PN, Luo X, Zhang P, et al. PGC-1alpha activator ZLN005 promotes maturation of cardiomyocytes derived from human embryonic stem cells. Aging (Albany NY). 2020;12(8):7411-30. https://doi. org/10.18632/aging.103088.

90. Zhou R, Li J, Zhang L, Cheng Y, Yan J, Sun Y, et al. Role of Parkin-mediated mitophagy in glucocorticoid-induced cardiomyocyte maturation. Life Sci. 2020;255:117817. https://doi.org/10.1016/j.lfs.2020.117817.

91. Chan NC, Salazar AM, Pham AH, Sweredoski MJ, Kolawa NJ, Graham RL, et al. Broad activation of the ubiquitin-proteasome system by Parkin is critical for mitophagy. Hum Mol Genet. 2011;20(9):1726-37. https://doi.org/1 0.1093/hmg/ddr048.

92. Kenny FM, Angsusingha K, Stinson D, Hotchkiss J. Unconjugated estrogens in the perinatal period. Pediatr Res. 1973;7(10):826-31. https://doi.org/10.12 03/00006450-197310000-00006.

93. Sakamoto T, Matsuura TR, Wan S, Ryba DM, Kim JU, Won KJ, et al. A critical role for estrogen-related receptor signaling in cardiac maturation. Circ Res. 2020;126(12):1685-702. https://doi.org/10.1161/CIRCRESAHA.119.316100.

94. Alaynick WA, Kondo RP, Xie W, He W, Dufour CR, Downes M, et al. ERRgamma directs and maintains the transition to oxidative metabolism in the postnatal heart. Cell Metab. 2007;6(1):13-24. https://doi.org/10.1016/j. cmet.2007.06.007.

95. Al Tanoury Z, Piskunov A, Rochette-Egly C. Vitamin C and retinoid signaling: genomic and nongenomic effects. J Lipid Res. 2013;54(7):1761-75. https:// doi.org/10.1194/jlr.R030833.

96. le Maire A, Teyssier C, Balaguer P, Bourguet W, Germain P. Regulation of RXR-RAR heterodimers by RXR- and RAR-specific ligands and their combinations. Cells. 2019;8(11) https://doi.org/10.3390/cells8111392.

97. Berggren Soderlund M, Fex GA, Nilsson-Ehle P. Concentrations of retinoids in early pregnancy and in newborns and their mothers. Am J Clin Nutr. 2005:81(3):633-6. https://doi.org/10.1093/ajcn/81.3.633.

98. Li E, Sucov HM, Lee KF, Evans RM, Jaenisch R. Normal development and growth of mice carrying a targeted disruption of the alpha 1 retinoic acid receptor gene. Proc Natl Acad Sci U S A. 1993;90(4):1590-4. https:/doi.org/10.1073/pnas.90.4.1590.

99. Luo J, Pasceri P, Conlon RA, Rossant J, Giquere V. Mice lacking all isoforms of retinoic acid receptor beta develop normally and are susceptible to the teratogenic effects of retinoic acid. Mech Dev. 1995;53(1):61-71. https://doi. org/10.1016/0925-4773(95)00424-6.

100. Lohnes D, Kastner P, Dierich A, Mark M, LeMeur M, Chambon P. Function of retinoic acid receptor gamma in the mouse. Cell. 1993;73(4):643-58. https:// doi.org/10.1016/0092-8674(93)90246-m.

101. Lohnes D, Mark M, Mendelsohn C, Dolle P, Dierich A, Gorry P, et al. Function of the retinoic acid receptors (RARs) during development (I). Craniofacial and skeletal abnormalities in RAR double mutants. Development. 1994; 120(10):2723-48.

102. Mendelsohn C, Lohnes D, Decimo D, Lufkin T, LeMeur M, Chambon P, et al. Function of the retinoic acid receptors (RARs) during development (II).
Multiple abnormalities at various stages of organogenesis in RAR double mutants. Development. 1994;120(10):2749-71.

103. Dyson E, Sucov HM, Kubalak SW, Schmid-Schonbein GW, DeLano FA, Evans RM, et al. Atrial-like phenotype is associated with embryonic ventricular failure in retinoid X receptor alpha -/- mice. Proc Natl Acad Sci U S A. 1995:92(16):7386-90. https://doi.org/10.1073/pnas.92.16.7386.

104. Kolodzinska A, Heleniak A, Ratajska A. Retinoic acid-induced ventricular noncompacted cardiomyopathy in mice. Kardiol Pol. 2013;71(5):447-52. https:// doi.org/10.5603/KP.2013.0090

105. Yasui H, Nakazawa M, Morishima M, Miyagawa-Tomita S, Momma K Morphological observations on the pathogenetic process of transposition of the great arteries induced by retinoic acid in mice. Circulation. 1995;91(9): 2478-86. https://doi.org/10.1161/01.cir.91.9.2478.

106. Guleria RS, Choudhary R, Tanaka T, Baker KM, Pan J. Retinoic acid receptormediated signaling protects cardiomyocytes from hyperglycemia induced apoptosis: role of the renin-angiotensin system. J Cell Physiol. 2011;226(5): 1292-307. https://doi.org/10.1002/jcp.22457.

107. Chai D, Lin X, Zheng Q, Xu C, Xie H, Ruan Q, et al. Retinoid X receptor agonists attenuates cardiomyopathy in streptozotocin-induced type 1 diabetes through LKB1-dependent anti-fibrosis effects. Clin Sci (Lond). 2020; 134(6):609-28. https://doi.org/10.1042/CS20190985.

108. Thomson DM. The Role of AMPK in the Regulation of Skeletal Muscle Size, Hypertrophy, and Regeneration. Int J Mol Sci. 2018;19(10) https://doi.org/1 0.3390/ijms19103125.

109. Miao S, Zhao D, Wang $X, N i$, Fang $X, Y u$ M, et al. Retinoic acid promotes metabolic maturation of human embryonic stem cell-derived cardiomyocytes. Theranostics. 2020;10(21):9686-701. https://doi.org/10.7150/ thno.44146.

110. Lee JH, Protze SI, Laksman Z, Backx PH, Keller GM. Human pluripotent stem cell-derived atrial and ventricular cardiomyocytes develop from distinct mesoderm populations. Cell Stem Cell. 2017;21(2):179-94 e4. https://doi. org/10.1016/j.stem.2017.07.003.

111. Vila Petroff MG, Mattiazzi AR. Angiotensin II and cardiac excitationcontraction coupling: questions and controversies. Heart Lung Circ. 2001; 10(2):90-8. https://doi.org/10.1046/j.1444-2892.2001.00083.x.

112. Broughton Pipkin F, Kirkpatrick SM, Lumbers ER, Mott JC. Renin and angiotensin-like levels in foetal, new-born and adult sheep. J Physiol. 1974; 241(3):575-88. https://doi.org/10.1113/jphysiol.1974.sp010672.

113. Lumbers ER, Reid GC. Effects of vaginal delivery and caesarian section on plasma renin activity and angiotensin II levels in human umbilical cord blood. Biol Neonate. 1977;31(1-2):127-33. https://doi.org/10.1159/00024 0953.

114. Bai L, Wang M, Zhang S, Yue M, Guo Y, Wang P, et al. AT1-receptor autoantibody exposure in utero contributes to cardiac dysfunction and increased glycolysis in fetal mice. Acta Biochim Biophys Sin (Shanghai). 2020; https://doi.org/10.1093/abbs/gmaa131.

115. Liu J, Li X, Lu Q, Ren D, Sun X, Rousselle T, et al. AMPK: a balancer of the renin-angiotensin system. Biosci Rep. 2019;39(9) https://doi.org/10.1042/ BSR20181994.

116. Wu L, Jia Z, Yan L, Wang W, Wang J, Zhang Y, et al. Angiotensin II promotes cardiac differentiation of embryonic stem cells via angiotensin type 1 receptor. Differentiation. 2013;86(1-2):23-9. https://doi.org/10.1016/j.diff.2 013.06.007.

117. Foldes G, Mioulane M, Wright JS, Liu AQ, Novak P, Merkely B, et al. Modulation of human embryonic stem cell-derived cardiomyocyte growth: a testbed for studying human cardiac hypertrophy? J Mol Cell Cardiol. 2011; 50(2):367-76. https://doi.org/10.1016/j.yjmcc.2010.10.029.

118. Stuck BJ, Lenski M, Bohm M, Laufs U. Metabolic switch and hypertrophy of cardiomyocytes following treatment with angiotensin II are prevented by AMP-activated protein kinase. J Biol Chem. 2008;283(47):32562-9. https:// doi.org/10.1074/jbc.M801904200.

119. Zhang Y, Yu B, He J, Chen D. From nutrient to MicroRNA: a novel insight into cell signaling involved in skeletal muscle development and disease. Int J Biol Sci. 2016;12(10):1247-61. https://doi.org/10.7150/ijbs.16463.

120. Zhao XY, Lin JD. Long noncoding RNAs: a new regulatory code in metabolic control. Trends Biochem Sci. 2015;40(10):586-96. https://doi.org/1 0.1016/j.tibs.2015.08.002

121. Pradas-Juni M, Hansmeier NR, Link JC, Schmidt E, Larsen BD, Klemm $P$, et al. A MAFG-IncRNA axis links systemic nutrient abundance to hepatic glucose metabolism. Nat Commun. 2020;11(1):644. https://doi.org/10.1038/s41467-02 $0-14323-y$. 
122. Pang JKS, Phua QH, Soh BS. Applications of miRNAs in cardiac development, disease progression and regeneration. Stem Cell Res Ther. 2019;10(1):336. https://doi.org/10.1186/s13287-019-1451-2.

123. Zhao Y, Ransom JF, Li A, Vedantham V, von Drehle M, Muth AN, et al. Dysregulation of cardiogenesis, cardiac conduction, and cell cycle in mice lacking miRNA-1-2. Cell. 2007;129(2):303-17. https://doi.org/10.1016/j.cell.2 007.03.030.

124. Ivey KN, Muth A, Arnold J, King FW, Yeh RF, Fish JE, et al. MicroRNA regulation of cell lineages in mouse and human embryonic stem cells. Cell Stem Cell. 2008;2(3):219-29. https://doi.org/10.1016/j.stem.2008.01.016.

125. Lu TY, Lin B, Li Y, Arora A, Han L, Cui C, et al. Overexpression of microRNA-1 promotes cardiomyocyte commitment from human cardiovascular progenitors via suppressing WNT and FGF signaling pathways. J Mol Cell Cardiol. 2013;63:146-54. https://doi.org/10.1016/j.yjmcc.2013.07.019.

126. Yang B, Lin H, Xiao J, Lu Y, Luo X, Li B, et al. The muscle-specific microRNA miR-1 regulates cardiac arrhythmogenic potential by targeting GJA1 and KCNJ2. Nat Med. 2007:13(4):486-91. https://doi.org/10.1038/nm1569.

127. Giuliani A, Prattichizzo F, Micolucci L, Ceriello A, Procopio AD, Rippo MR. Mitochondrial (Dys) function in inflammaging: do MitomiRs influence the energetic, oxidative, and inflammatory status of senescent cells? Mediators Inflamm. 2017;2017:2309034. https://doi.org/10.1155/2017/2309034.

128. Ugalde AP, Espanol Y, Lopez-Otin C. Micromanaging aging with miRNAs: new messages from the nuclear envelope. Nucleus. 2011;2(6):549-55. https://doi.org/10.4161/nucl.2.6.17986

129. Lee S, Lim S, Ham O, Lee SY, Lee CY, Park JH, et al. ROS-mediated bidirectional regulation of miRNA results in distinct pathologic heart conditions. Biochem Biophys Res Commun. 2015;465(3):349-55. https://doi. org/10.1016/j.bbrc.2015.07.160.

130. Wang L, Yuan Y, Li J, Ren H, Cai Q, Chen X, et al. MicroRNA-1 aggravates cardiac oxidative stress by post-transcriptional modification of the antioxidant network. Cell Stress Chaperones. 2015;20(3):411-20. https://doi. org/10.1007/s12192-014-0565-9.

131. Sun Y, Ge Y, Drnevich J, Zhao Y, Band M, Chen J. Mammalian target of rapamycin regulates miRNA-1 and follistatin in skeletal myogenesis. J Cell Biol. 2010;189(7):1157-69. https://doi.org/10.1083/jcb.200912093.

132. Yu XY, Song YH, Geng YJ, Lin QX, Shan ZX, Lin SG, et al. Glucose induces apoptosis of cardiomyocytes via microRNA-1 and IGF-1. Biochem Biophys Res Commun. 2008;376(3):548-52. https://doi.org/10.1016/j.bbrc.2008.09.025.

133. Yu L, Yu H, Li X, Jin C, Zhao Y, Xu S, et al. P38 MAPK/miR-1 are involved in the protective effect of EGCG in high glucose-induced $\mathrm{C} \times 43$ downregulation in neonatal rat cardiomyocytes. Cell Biol Int. 2016;40(8): 934-42. https://doi.org/10.1002/cbin.10637.

134. Cheng Y, Zhang D, Zhu M, Wang Y, Guo S, Xu B, et al. Liver X receptor alpha is targeted by microRNA-1 to inhibit cardiomyocyte apoptosis through a ROS-mediated mitochondrial pathway. Biochem Cell Biol. 2018; 96(1):11-8. https://doi.org/10.1139/bcb-2017-0154.

135. Wang $Y$, Sun $X$. The functions of LncRNA in the heart. Diabetes Res Clin Pract. 2020;168:108249. https://doi.org/10.1016/j.diabres.2020.108249

136. Han X, Zhang J, Liu Y, Fan X, Ai S, Luo Y, et al. The IncRNA Hand2os1/Uph locus orchestrates heart development through regulation of precise expression of Hand2. Development. 2019;146(13) https:/doi.org/10.1242/dev.176198.

137. Pant T, Dhanasekaran A, Bai X, Zhao M, Thorp EB, Forbess JM, et al. Genome-wide differential expression profiling of IncRNAs and mRNAs associated with early diabetic cardiomyopathy. Sci Rep. 2019;9(1):15345. https://doi.org/10.1038/s41598-019-51872-9.

138. Lei S, She Y, Zeng J, Chen R, Zhou S, Shi H. Expression patterns of regulatory IncRNAs and miRNAs in muscular atrophy models induced by starvation in vitro and in vivo. Mol Med Rep. 2019;20(5):4175-85. https://doi. org/10.3892/mmr.2019.10661.

139. Touma M, Kang X, Zhao Y, Cass AA, Gao F, Biniwale R, et al. Decoding the long noncoding RNA during cardiac maturation: a roadmap for functional discovery. Circ Cardiovasc Genet. 2016;9(5):395-407. https://doi.org/10.1161/ CIRCGENETICS.115.001363.

140. Yang X, Qian K. Protein O-GlcNAcylation: emerging mechanisms and functions. Nat Rev Mol Cell Biol. 2017;18(7):452-65. https://doi.org/10.1038/nrm.2017.22.

141. Harwood KR, Hanover JA. Nutrient-driven O-GlcNAc cycling - think globally but act locally. J Cell Sci. 2014;127(Pt 9):1857-67. https://doi.org/10.1242/ jcs.113233.

142. Collins HE, Chatham JC. Regulation of cardiac O-GICNAcylation: more than just nutrient availability. Biochim Biophys Acta Mol Basis Dis. 2020;1866(5): 165712. https://doi.org/10.1016/j.bbadis.2020.165712.
143. Tan EP, Villar MT, E L, Lu J, Selfridge JE, Artigues A, et al. Altering O-linked beta-N-acetylglucosamine cycling disrupts mitochondrial function. J Bio Chem. 2014;289(21):14719-30. https://doi.org/10.1074/jbc.M113.525790.

144. Mu Y, Yu H, Wu T, Zhang J, Evans SM. Chen J. O-linked beta-Nacetylglucosamine transferase plays an essential role in heart development through regulating angiopoietin-1. PLoS Genet. 2020;16(4):e1008730. https://doi.org/10.1371/journal.pgen.1008730.

145. Watson LJ, Long BW, DeMartino AM, Brittian KR, Readnower RD, Brainard RE, et al. Cardiomyocyte Ogt is essential for postnatal viability. Am J Physiol Heart Circ Physiol. 2014;306(1):H142-53. https://doi.org/10.1152/ajpheart. 00438.2013.

146. Yu H, Wen L, O-GlcNAcylation MY. Is essential for autophagy in cardiomyocytes. Oxid Med Cell Longev. 2020;2020:5602396. https://doi.org/1 $0.1155 / 2020 / 5602396$.

147. Kim HS, Park SY, Choi YR, Kang JG, Joo HJ, Moon WK, et al. Excessive OGlcNAcylation of proteins suppresses spontaneous cardiogenesis in ES cells. FEBS Lett. 2009;583(15):2474-8. https://doi.org/10.1016/j.febslet.2009.06.052.

148. Champattanachai V, Marchase RB, Chatham JC. Glucosamine protects neonatal cardiomyocytes from ischemia-reperfusion injury via increased protein-associated O-GICNAc. Am J Physiol Cell Physiol. 2007;292(1):C178-87. https://doi.org/10.1152/ajpcell.00162.2006.

149. Fricovsky ES, Suarez J, Ihm SH, Scott BT, Suarez-Ramirez JA, Banerjee I, et al. Excess protein O-GICNAcylation and the progression of diabetic cardiomyopathy. Am J Physiol Regul Integr Comp Physiol. 2012;303(7):R689_ 99. https://doi.org/10.1152/ajpregu.00548.2011.

150. Erickson JR, Pereira L, Wang L, Han G, Ferguson A, Dao K, et al. Diabetic hyperglycaemia activates CaMKII and arrhythmias by O-linked glycosylation. Nature. 2013;502(7471):372-6. https://doi.org/10.1038/nature12537.

151. Zhao Q, Sun Q, Zhou L, Liu K, Jiao K. Complex regulation of mitochondrial function during cardiac development. J Am Heart Assoc. 2019;8(13): e012731. https://doi.org/10.1161/JAHA.119.012731.

152. Smolich JJ. Ultrastructural and functional features of the developing mammalian heart: a brief overview. Reprod Fertil Dev. 1995;7(3):451-61. https://doi.org/10.1071/rd9950451.

153. Porter GA Jr, Hom J, Hoffman D, Quintanilla R, de Mesy Bentley K, Sheu SS. Bioenergetics, mitochondria, and cardiac myocyte differentiation. Prog Pediatr Cardiol. 2011;31(2):75-81. https://doi.org/10.1016/j.ppedcard.2011.02. 002.

154. Lai L, Leone TC, Zechner C, Schaeffer PJ, Kelly SM, Flanagan DP, et al. Transcriptional coactivators PGC-1alpha and PGC-Ibeta control overlapping programs required for perinatal maturation of the heart. Genes Dev. 2008; 22(14):1948-61. https://doi.org/10.1101/gad.1661708.

155. Venkatesh S, Baljinnyam E, Tong M, Kashihara T, Yan L, Liu T, et al. Proteomic analysis of mitochondrial biogenesis in cardiomyocytes differentiated from human induced pluripotent stem cells. Am J Physiol Regul Integr Comp Physiol. 2020; https://doi.org/10.1152/ajpregu.00207.202

156. Zhang T, Liu CF, Zhang TN, Wen R, Song WL. Overexpression of peroxisome proliferator-activated receptor gamma coactivator 1-alpha protects cardiomyocytes from lipopolysaccharide-induced mitochondrial damage and apoptosis. Inflammation. 2020;43(5):1806-20. https://doi.org/10.1007/s1 0753-020-01255-4

157. Ng R, Sewanan LR, Brill AL, Stankey P, Li X, Qyang Y, et al. Contractile work directly modulates mitochondrial protein levels in human engineered heart tissues. Am J Physiol Heart Circ Physiol. 2020;318(6):H1516-H24. https://doi. org/10.1152/ajpheart.00055.2020.

158. Hang W, He B, Chen J, Xia L, Wen B, Liang T, et al. Berberine ameliorates high glucose-induced cardiomyocyte injury via AMPK signaling activation to stimulate mitochondrial biogenesis and restore autophagic flux. Front Pharmacol. 2018:9:1121. https://doi.org/10.3389/fphar.2018.01121.

159. Tao L, Huang X, Xu M, Yang L, Hua F. MiR-144 protects the heart from hyperglycemia-induced injury by regulating mitochondrial biogenesis and cardiomyocyte apoptosis. FASEB J. 2020;34(2):2173-97. https://doi.org/10.1 096/fj.201901838R

160. Bustillo-Zabalbeitia I, Montessuit S, Raemy E, Basanez G, Terrones O, Martinou JC. Specific interaction with cardiolipin triggers functional activation of Dynamin-Related Protein 1. PLoS One. 2014;9(7):e102738. https://doi.org/10.1371/journal.pone.0102738.

161. Tilokani L, Nagashima S, Paupe V, Prudent J. Mitochondrial dynamics: overview of molecular mechanisms. Essays Biochem. 2018;62(3):341-60. https://doi.org/10.1042/EBC20170104. 
162. Kane LA, Youle RJ. Mitochondrial fission and fusion and their roles in the heart. J Mol Med (Berl). 2010;88(10):971-9. https://doi.org/10.1007/s00109-01 0-0674-6.

163. Dorn GW 2nd, Vega RB, Kelly DP. Mitochondrial biogenesis and dynamics in the developing and diseased heart. Genes Dev. 2015;29(19):1981-91. https:// doi.org/10.1101/gad.269894.115.

164. Papanicolaou KN, Ngoh GA, Dabkowski ER, O'Connell KA, Ribeiro RF Jr, Stanley WC, et al. Cardiomyocyte deletion of mitofusin-1 leads to mitochondrial fragmentation and improves tolerance to ROS-induced mitochondrial dysfunction and cell death. Am J Physiol Heart Circ Physiol. 2012;302(1):H167-79. https://doi.org/10.1152/ajpheart.00833.2011.

165. Papanicolaou KN, Khairallah RJ, Ngoh GA, Chikando A, Luptak I, O'Shea KM, et al. Mitofusin-2 maintains mitochondrial structure and contributes to stress-induced permeability transition in cardiac myocytes. Mol Cell Biol. 2011;31(6):1309-28. https://doi.org/10.1128/MCB.00911-10.

166. Chen Y, Liu Y, Dorn GW 2nd. Mitochondrial fusion is essential for organelle function and cardiac homeostasis. Circ Res. 2011;109(12):1327-31. https:// doi.org/10.1161/CIRCRESAHA.111.258723.

167. Song M, Mihara K, Chen Y, Scorrano L, Dorn GW 2nd. Mitochondrial fission and fusion factors reciprocally orchestrate mitophagic culling in mouse hearts and cultured fibroblasts. Cell Metab. 2015;21(2):273-86. https://doi. org/10.1016/j.cmet.2014.12.011.

168. Song M, Franco A, Fleischer JA, Zhang L, Dorn GW 2nd. Abrogating mitochondrial dynamics in mouse hearts accelerates mitochondrial senescence. Cell Metab. 2017;26(6):872-83 e5. https://doi.org/10.1016/j. cmet.2017.09.023.

169. Xin T, Lv W, Liu D, Jing Y, Hu F. Opa1 reduces hypoxia-induced cardiomyocyte death by improving mitochondrial quality control. Front Cell Dev Biol. 2020;8:853. https://doi.org/10.3389/fcell.2020.00853.

170. Piquereau J, Caffin F, Novotova M, Prola A, Garnier A, Mateo P, et al. Downregulation of OPA1 alters mouse mitochondrial morphology, PTP function and cardiac adaptation to pressure overload. Cardiovasc Res. 2012;94(3): 408-17. https://doi.org/10.1093/cvr/cvs117.

171. Wai T, Garcia-Prieto J, Baker MJ, Merkwirth C, Benit P, Rustin P, et al. Imbalanced OPA1 processing and mitochondrial fragmentation cause heart failure in mice. Science. 2015;350(6265):aad0116. https://doi.org/10.1126/ science.aad0116.

172. Kasahara A, Cipolat S, Chen Y, Dorn GW 2nd, Scorrano L. Mitochondrial fusion directs cardiomyocyte differentiation via calcineurin and Notch signaling. Science. 2013;342(6159):734-7. https://doi.org/10.1126/ science.1241359.

173. Lees JG, Kong AM, Chen YC, Sivakumaran P, Hernandez D, Pebay A, et al. Mitochondrial fusion by M1 promotes embryoid body cardiac differentiation of human pluripotent stem cells. Stem Cells Int. 2019;2019: 6380135. https://doi.org/10.1155/2019/6380135.

174. Hoque A, Sivakumaran P, Bond ST, Ling NXY, Kong AM, Scott JW, et al. Mitochondrial fission protein Drp1 inhibition promotes cardiac mesodermal differentiation of human pluripotent stem cells. Cell Death Discov. 2018:4:39. https://doi.org/10.1038/s41420-018-0042-9.

175. Ishihara T, Ban-Ishihara R, Maeda M, Matsunaga Y, Ichimura A, Kyogoku S, et al. Dynamics of mitochondrial DNA nucleoids regulated by mitochondrial fission is essential for maintenance of homogeneously active mitochondria during neonatal heart development. Mol Cell Biol. 2015;35(1):211-23. https://doi.org/10.1128/MCB.01054-14.

176. Adaniya SM, O-Uchi J, Cypress MW, Kusakari Y, Jhun BS. Posttranslational modifications of mitochondrial fission and fusion proteins in cardiac physiology and pathophysiology. Am J Physiol Cell Physiol. 2019;316(5): C583-604. https://doi.org/10.1152/ajpcell.00523.2018.

177. Yu J, Maimaitili Y, Xie P, Wu JJ, Wang J, Yang YN, et al. High glucose concentration abrogates sevoflurane post-conditioning cardioprotection by advancing mitochondrial fission but dynamin-related protein 1 inhibitor restores these effects. Acta Physiol (Oxf). 2017;220(1):83-98. https://doi.org/1 $0.1111 / a p h a .12812$

178. Yu T, Sheu SS, Robotham JL, Yoon Y. Mitochondrial fission mediates high glucose-induced cell death through elevated production of reactive oxygen species. Cardiovasc Res. 2008;79(2):341-51. https://doi.org/10.1093/cvr/cvn104.

179. Jang WB, Park JH, Ji ST, Lee NK, Kim DY, Kim YJ, et al. Cytoprotective roles of a novel compound, MHY-1684, against hyperglycemia-induced oxidative stress and mitochondrial dysfunction in human cardiac progenitor cells. Oxid Med Cell Longev. 2018;2018:4528184. https://doi.org/10.1155/2018/452 8184
180. Ikeda Y, Shirakabe A, Maejima Y, Zhai P, Sciarretta S, Toli J, et al. Endogenous Drp1 mediates mitochondrial autophagy and protects the heart against energy stress. Circ Res. 2015;116(2):264-78. https://doi.org/1 $0.1161 /$ CIRCRESAHA.116.303356.

181. Chen Z, Li Y, Jiang G, Yang C, Wang Y, Wang X, et al. Knockdown of LRP6 activates Drp1 to inhibit survival of cardiomyocytes during glucose deprivation. Biomed Pharmacother. 2018;103:1408-14. https://doi.org/10.101 6/j.biopha.2018.04.134

182. Ding M, Feng N, Tang D, Feng J, Li Z, Jia M, et al. Melatonin prevents Drp1mediated mitochondrial fission in diabetic hearts through SIRT1-PGC1alpha pathway. J Pineal Res. 2018;65(2):e12491. https://doi.org/10.1111/jpi.12491.

183. Hu Q, Zhang H, Gutierrez Cortes N, Wu D, Wang P, Zhang J, et al. Increased Drp1 acetylation by lipid overload induces cardiomyocyte death and heart dysfunction. Circ Res. 2020;126(4):456-70. https://doi.org/10.1161/CIRCRESA HA.119.315252.

184. Hom J, Yu T, Yoon Y, Porter G, Sheu SS. Regulation of mitochondrial fission by intracellular $\mathrm{Ca} 2+$ in rat ventricular myocytes. Biochim Biophys Acta. 2010;1797(6-7):913-21. https://doi.org/10.1016/j.bbabio.2010.03.018.

185. Haworth RA, Hunter DR. The Ca2+-induced membrane transition in mitochondria. II. Nature of the Ca2+ trigger site. Arch Biochem Biophys. 1979:195(2):460-7. https://doi.org/10.1016/0003-9861(79)90372-2.

186. Hom JR, Quintanilla RA, Hoffman DL, de Mesy Bentley KL, Molkentin JD, Sheu SS, et al. The permeability transition pore controls cardiac mitochondrial maturation and myocyte differentiation. Dev Cell. 2011;21(3): 469-78. https://doi.org/10.1016/j.devcel.2011.08.008.

187. Lingan JV, Alanzalon RE, Porter GA Jr. Preventing permeability transition pore opening increases mitochondrial maturation, myocyte differentiation and cardiac function in the neonatal mouse heart. Pediatr Res. 2017;81(6): 932-41. https://doi.org/10.1038/pr.2017.19.

188. Cho SW, Park JS, Heo HJ, Park SW, Song S, Kim I, et al. Dual modulation of the mitochondrial permeability transition pore and redox signaling synergistically promotes cardiomyocyte differentiation from pluripotent stem cells. J Am Heart Assoc. 2014;3(2):e000693. https://doi.org/10.1161/JA HA.113.000693.

189. Bauer TM, Murphy E. Role of mitochondrial calcium and the permeability transition pore in regulating cell death. Circ Res. 2020;126(2):280-93. https:// doi.org/10.1161/CIRCRESAHA.119.316306.

190. Zaha VG, Qi D, Su KN, Palmeri M, Lee HY, Hu X, et al. AMPK is critical for mitochondrial function during reperfusion after myocardial ischemia. J Mol Cell Cardiol. 2016;91:104-13. https://doi.org/10.1016/j.yjmcc.2015.12.032.

191. Lee SB, Kim JJ, Han SA, Fan Y, Guo LS, Aziz K, et al. The AMPK-Parkin axis negatively regulates necroptosis and tumorigenesis by inhibiting the necrosome. Nat Cell Biol. 2019;21(8):940-51. https://doi.org/10.1038/s41556019-0356-8

192. Sun T, Ding W, Xu T, Ao X, Yu T, Li M, et al. Parkin regulates programmed necrosis and myocardial ischemia/reperfusion injury by targeting cyclophilin-D. Antioxid Redox Signal. 2019;31(16):1177-93. https://doi.org/1 0.1089/ars.2019.7734

193. Nguyen TN, Padman BS, Lazarou M. Deciphering the molecular signals of PINK1/Parkin mitophagy. Trends Cell Biol. 2016;26(10):733-44. https://doi. org/10.1016/j.tcb.2016.05.008.

194. Jin SM, Youle RJ. PINK1- and Parkin-mediated mitophagy at a glance. J Cell Sci. 2012;125(Pt 4):795-9. https://doi.org/10.1242/jcs.093849.

195. Gong G, Song M, Csordas G, Kelly DP, Matkovich SJ, Dorn GW 2nd. Parkinmediated mitophagy directs perinatal cardiac metabolic maturation in mice Science. 2015;350(6265):aad2459. https://doi.org/10.1126/science.aad2459.

196. Seabright AP, Fine NHF, Barlow JP, Lord SO, Musa I, Gray A, et al. AMPK activation induces mitophagy and promotes mitochondrial fission while activating TBK1 in a PINK1-Parkin independent manner. FASEB J. 2020;34(5): 6284-301. https://doi.org/10.1096/fj.201903051R.

197. Bordi M, Darji S, Sato Y, Mellen M, Berg MJ, Kumar A, et al. mTOR hyperactivation in Down Syndrome underlies deficits in autophagy induction, autophagosome formation, and mitophagy. Cell Death Dis. 2019; 10(8):563. https://doi.org/10.1038/s41419-019-1752-5.

198. Andres AM, Hernandez G, Lee P, Huang C, Ratliff EP, Sin J, et al. Mitophagy is required for acute cardioprotection by simvastatin. Antioxid Redox Signal. 2014;21(14):1960-73. https://doi.org/10.1089/ars.2013.5416.

199. Wang B, Nie J, Wu L, Hu Y, Wen Z, Dong L, et al. AMPKalpha2 protects against the development of heart failure by enhancing mitophagy via PINK1 phosphorylation. Circ Res. 2018;122(5):712-29. https://doi.org/10.1161/ CIRCRESAHA.117.312317. 
200. Shao D, Kolwicz SC Jr, Wang P, Roe ND, Villet O, Nishi K, et al. Increasing fatty acid oxidation prevents high-fat diet-induced cardiomyopathy through regulating parkin-mediated mitophagy. Circulation. 2020;142(10):983-97. https://doi.org/10.1161/CIRCULATIONAHA.119.043319.

201. Manzella N, Santin Y, Maggiorani D, Martini H, Douin-Echinard V, Passos JF, et al. Monoamine oxidase-A is a novel driver of stress-induced premature senescence through inhibition of parkin-mediated mitophagy. Aging Cell. 2018;17(5):e12811. https://doi.org/10.1111/acel.12811.

202. Momtahan N, Crosby CO, Zoldan J. The role of reactive oxygen species in in vitro cardiac maturation. Trends Mol Med. 2019;25(6):482-93. https://doi. org/10.1016/j.molmed.2019.04.005.

203. Rhee SG. Cell signaling. H2O2, a necessary evil for cell signaling. Science. 2006;312(5782):1882-3. https://doi.org/10.1126/science.1130481.

204. Seok H, Lee H, Lee S, Ahn SH, Lee HS, Kim GD, et al. Position-specific oxidation of miR-1 encodes cardiac hypertrophy. Nature. 2020;584(7820): 279-85. https://doi.org/10.1038/s41586-020-2586-0.

205. Tu C, Allen A, Deng W, Conroy O, Nambiar M, Zoldan J. Commonly used thiol-containing antioxidants reduce cardiac differentiation and alter gene expression ratios of sarcomeric isoforms. Exp Cell Res. 2018;370(1):150-9. https://doi.org/10.1016/j.yexcr.2018.06.017.

206. Sauer H, Rahimi G, Hescheler J, Wartenberg M. Role of reactive oxygen species and phosphatidylinositol 3-kinase in cardiomyocyte differentiation of embryonic stem cells. FEBS Lett. 2000;476(3):218-23. https://doi.org/10.1 016/s0014-5793(00)01747-6.

207. Crespo FL, Sobrado VR, Gomez L, Cervera AM, McCreath KJ. Mitochondrial reactive oxygen species mediate cardiomyocyte formation from embryonic stem cells in high glucose. Stem Cells. 2010;28(7):1132-42. https://doi.org/1 0.1002/stem.441.

208. Birket MJ, Casini S, Kosmidis G, Elliott DA, Gerencser AA, Baartscheer A, et al. PGC-1alpha and reactive oxygen species regulate human embryonic stem cell-derived cardiomyocyte function. Stem Cell Reports. 2013;1(6):560-74. https://doi.org/10.1016/.j.stemcr.2013.11.008.

209. Goldhaber JI, Ji S, Lamp ST, Weiss JN. Effects of exogenous free radicals on electromechanical function and metabolism in isolated rabbit and guinea pig ventricle. Implications for ischemia and reperfusion injury. J Clin Invest. 1989;83(6):1800-9. https://doi.org/10.1172/JCl114085.

210. Guerra L, Cerbai E, Gessi S, Borea PA, Mugelli A. The effect of oxygen free radicals on calcium current and dihydropyridine binding sites in guinea-pig ventricular myocytes. Br J Pharmacol. 1996;118(5):1278-84. https://doi.org/1 0.1111/j.1476-5381.1996.tb15534.x.

211. Antico Arciuch VG, Elguero ME, Poderoso JJ, Carreras MC. Mitochondrial regulation of cell cycle and proliferation. Antioxid Redox Signal. 2012;16(10): 1150-80. https://doi.org/10.1089/ars.2011.4085.

212. Lopez-Mejia IC, Fajas L. Cell cycle regulation of mitochondrial function. Curr Opin Cell Biol. 2015;33:19-25. https://doi.org/10.1016/j.ceb.2014.10.006.

213. Matsuyama D, Kawahara K. Oxidative stress-induced formation of a positivefeedback loop for the sustained activation of p38 MAPK leading to the loss of cell division in cardiomyocytes soon after birth. Basic Res Cardiol. 2011; 106(5):815-28. https://doi.org/10.1007/s00395-011-0178-8.

214. Puente BN, Kimura W, Muralidhar SA, Moon J, Amatruda JF, Phelps KL, et al. The oxygen-rich postnatal environment induces cardiomyocyte cell-cycle arrest through DNA damage response. Cell. 2014;157(3):565-79. https://doi. org/10.1016/j.cell.2014.03.032.

215. Cardoso AC, Lam NT, Savla JJ, Nakada Y, Pereira AHM, Elnwasany A, et al. Mitochondrial substrate utilization regulates cardiomyocyte cell cycle progression. Nat Metab. 2020;2(2):167-78.

216. Mahmoud Al, Kocabas F, Muralidhar SA, Kimura W, Koura AS, Thet S, et al. Meis1 regulates postnatal cardiomyocyte cell cycle arrest. Nature. 2013; 497(7448):249-53. https://doi.org/10.1038/nature12054.

217. Lindgren IM, Drake RR, Chattergoon NN, Thornburg KL. Down-regulation of MEIS1 promotes the maturation of oxidative phosphorylation in perinatal cardiomyocytes. FASEB J. 2019;33(6):7417-26. https://doi.org/10.1096/fj.201 801330RR.

218. Blasco N, Bea A, Bares G, Giron C, Navaridas R, Irazoki A, et al. Involvement of the mitochondrial nuclease EndoG in the regulation of cell proliferation through the control of reactive oxygen species. Redox Biol. 2020;37:101736. https://doi.org/10.1016/j.redox.2020.101736.

219. Zhang D, Li Y, Heims-Waldron D, Bezzerides V, Guatimosim S, Guo Y, et al. Mitochondrial cardiomyopathy caused by elevated reactive oxygen species and impaired cardiomyocyte proliferation. Circ Res. 2018;122(1):74-87. https://doi.org/10.1161/CIRCRESAHA.117.311349.
220. Bergmann O, Bhardwaj RD, Bernard S, Zdunek S, Barnabe-Heider F, Walsh S, et al. Evidence for cardiomyocyte renewal in humans. Science. 2009; 324(5923):98-102. https://doi.org/10.1126/science.1164680.

221. van Velthoven CTJ, Rando TA. Stem cell quiescence: dynamism, restraint, and cellular idling. Cell Stem Cell. 2019;24(2):213-25. https://doi.org/10.1016/ j.stem.2019.01.001.

222. Mao Z, Ke Z, Gorbunova V, Seluanov A. Replicatively senescent cells are arrested in G1 and G2 phases. Aging (Albany NY). 2012;4(6):431-5. https:// doi.org/10.18632/aging.100467.

223. Maciel-Baron LA, Moreno-Blas D, Morales-Rosales SL, Gonzalez-Puertos WY Lopez-Diazguerrero NE, Torres C, et al. Cellular senescence, neurological function, and redox state. Antioxid Redox Signal. 2018;28(18):1704-23. https://doi.org/10.1089/ars.2017.7112.

224. Blazer S, Khankin E, Segev Y, Ofir R, Yalon-Hacohen M, Kra-Oz Z, et al. High glucose-induced replicative senescence: point of no return and effect of telomerase. Biochem Biophys Res Commun. 2002;296(1):93-101. https://doi. org/10.1016/s0006-291x(02)00818-5.

225. Colavitti R, Finkel T. Reactive oxygen species as mediators of cellular senescence. IUBMB Life. 2005;57(4-5):277-81. https://doi.org/10.1080/1521 6540500091890 .

226. Chow HM, Shi M, Cheng A, Gao Y, Chen G, Song X, et al. Age-related hyperinsulinemia leads to insulin resistance in neurons and cell-cycleinduced senescence. Nat Neurosci. 2019;22(11):1806-19. https://doi.org/10.1 038/s41593-019-0505-1.

227. Lundy SD, Zhu WZ, Regnier M, Laflamme MA. Structural and functional maturation of cardiomyocytes derived from human pluripotent stem cells. Stem Cells Dev. 2013;22(14):1991-2002. https://doi.org/10.1089/scd.2012.04 90.

228. Kim YY, Ku SY, Huh Y, Liu HC, Kim SH, Choi YM, et al. Anti-aging effects of vitamin $C$ on human pluripotent stem cell-derived cardiomyocytes. Age (Dordr). 2013;35(5):1545-57. https://doi.org/10.1007/s11357-012-9457-z.

229. Ozcebe SG, Bahcecioglu G, Yue XS, Zorlutuna P. Effect of cellular and ECM aging on human iPSC-derived cardiomyocyte performance, maturity and senescence. Biomaterials. 2020;268:120554. https://doi.org/10.1016/j.bioma terials.2020.120554.

230. Garbern JC, Helman A, Sereda R, Sarikhani M, Ahmed A, Escalante GO, et al. Inhibition of mTOR signaling enhances maturation of cardiomyocytes derived from human-induced pluripotent stem cells via p53-induced quiescence. Circulation. 2020;141(4):285-300. https://doi.org/10.1161/ CIRCULATIONAHA.119.044205.

231. Korotchkina LG, Leontieva OV, Bukreeva El, Demidenko ZN, Gudkov AV, Blagosklonny MV. The choice between p53-induced senescence and quiescence is determined in part by the mTOR pathway. Aging (Albany NY). 2010;2(6):344-52. https://doi.org/10.18632/aging.100160.

232. Riedl A, Schlederer M, Pudelko K, Stadler M, Walter S, Unterleuthner D, et al. Comparison of cancer cells in 2D vs 3D culture reveals differences in AKTmTOR-S6K signaling and drug responses. J Cell Sci. 2017;130(1):203-18. https://doi.org/10.1242/jcs.188102.

233. Hu M, Wang J. Mitochondrial metabolism and the maintenance of hematopoietic stem cell quiescence. Curr Opin Hematol. 2019;26(4):228-34. https://doi.org/10.1097/MOH.0000000000000507.

234. Aulestia FJ, Neant I, Dong J, Haiech J, Kilhoffer MC, Moreau M, et al. Quiescence status of glioblastoma stem-like cells involves remodelling of $\mathrm{Ca}(2+)$ signalling and mitochondrial shape. Sci Rep. 2018;8(1):9731. https:// doi.org/10.1038/s41598-018-28157-8.

235. Hinge A, He J, Bartram J, Javier J, Xu J, Fjellman E, et al. Asymmetrically segregated mitochondria provide cellular memory of hematopoietic stem cell replicative history and drive HSC attrition. Cell Stem Cell. 2020;26(3): 420-30 e6. https://doi.org/10.1016/j.stem.2020.01.016.

236. Fujimaki K, Li R, Chen H, Della Croce K, Zhang HH, Xing J, et al. Graded regulation of cellular quiescence depth between proliferation and senescence by a lysosomal dimmer switch. Proc Natl Acad Sci U S A. 2019; 116(45):22624-34. https://doi.org/10.1073/pnas.1915905116.

237. Gilsbach R, Preissl S, Gruning BA, Schnick T, Burger L, Benes V, et al. Dynamic DNA methylation orchestrates cardiomyocyte development, maturation and disease. Nat Commun. 2014;5:5288. https://doi.org/10.1038/ncomms6288.

238. Zhao W, Liu L, Pan B, Xu Y, Zhu J, Nan C, et al. Epigenetic regulation of cardiac myofibril gene expression during heart development. Cardiovasc Toxicol. 2015;15(3):203-9. https://doi.org/10.1007/s12012-014-9278-7.

239. Fujita J, Tohyama S, Kishino Y, Okada M, Concise Review MY. Genetic and epigenetic regulation of cardiac differentiation from human pluripotent 
stem cells. Stem Cells. 2019;37(8):992-1002. https://doi.org/10.1002/stem.302 7.

240. Joshi RO, Chellappan S, Kukshal P. Exploring the role of maternal nutritional epigenetics in congenital heart disease. Curr Dev Nutr. 2020;4(11):nzaa166. https://doi.org/10.1093/cdn/nzaa166.

241. Chowdhury S, Erickson SW, MacLeod SL, Cleves MA, Hu P, Karim MA, et al. Maternal genome-wide DNA methylation patterns and congenital heart defects. PLoS One. 2011;6(1):e16506. https://doi.org/10.1371/journal.pone. 0016506.

242. Biermann M, Cai W, Lang D, Hermsen J, Profio L, Zhou Y, et al. Epigenetic priming of human pluripotent stem cell-derived cardiac progenitor cells accelerates cardiomyocyte maturation. Stem Cells. 2019;37(7):910-23. https://doi.org/10.1002/stem.3021.

243. Kou CY, Lau SL, Au KW, Leung PY, Chim SS, Fung KP, et al. Epigenetic regulation of neonatal cardiomyocytes differentiation. Biochem Biophys Res Commun. 2010;400(2):278-83. https://doi.org/10.1016/j.bbrc.2010.08.064.

244. Lock MC, Tellam RL, Botting KJ, Wang KCW, Selvanayagam JB, Brooks DA, et al. The role of miRNA regulation in fetal cardiomyocytes, cardiac maturation and the risk of heart disease in adults. J Physiol. 2018;596(23): 5625-40. https://doi.org/10.1113/JP276072.

245. Kumar N, Dougherty JA, Manring HR, Elmadbouh I, Mergaye M, Czirok A, et al. Assessment of temporal functional changes and miRNA profiling of human iPSC-derived cardiomyocytes. Sci Rep. 2019;9(1):13188. https://doi. org/10.1038/s41598-019-49653-5.

246. Poon EN, Hao B, Guan D, Jun Li M, Lu J, Yang Y, et al. Integrated transcriptomic and regulatory network analyses identify microRNA-200c as a novel repressor of human pluripotent stem cell-derived cardiomyocyte differentiation and maturation. Cardiovasc Res. 2018;114(6):894-906. https:// doi.org/10.1093/cvr/cvy019

247. Jusic A, Devaux Y, EU-CC A. Mitochondrial noncoding RNA-regulatory network in cardiovascular disease. Basic Res Cardiol. 2020;115(3):23. https:// doi.org/10.1007/s00395-020-0783-5.

248. Song $\mathrm{R}, \mathrm{Hu} X \mathrm{X}$, Zhang L. Mitochondrial MiRNA in cardiovascular function and disease. Cells. 2019;8(12) https://doi.org/10.3390/cells8121475.

249. Carey BW, Finley LW, Cross JR, Allis CD, Thompson CB. Intracellular alphaketoglutarate maintains the pluripotency of embryonic stem cells. Nature. 2015;518(7539):413-6. https://doi.org/10.1038/nature13981.

250. Wellen KE, Hatzivassiliou G, Sachdeva UM, Bui TV, Cross JR, Thompson CB. ATP-citrate lyase links cellular metabolism to histone acetylation. Science. 2009;324(5930):1076-80. https://doi.org/10.1126/science.1164097.

251. Su X, Wellen KE, Rabinowitz JD. Metabolic control of methylation and acetylation. Curr Opin Chem Biol. 2016;30:52-60. https://doi.org/10.1016/j. cbpa.2015.10.030.

252. Santos $\mathrm{JH}$. Mitochondria signaling to the epigenome: a novel role for an old organelle. Free Radic Biol Med. 2020; https://doi.org/10.1016/j.freera dbiomed.2020.11.016.

253. Kim SY, Zhang X, Schiattarella GG, Altamirano F, Ramos TAR, French KM, et al. Epigenetic reader BRD4 (bromodomain-containing protein 4) governs nucleus-encoded mitochondrial transcriptome to regulate cardiac function. Circulation. 2020;142(24):2356-70. https://doi.org/10.1161/CIRCULATIONA HA.120.047239.

254. Padmanabhan A, Alexanian M, Linares-Saldana R, Gonzalez-Teran B, Andreoletti G, Huang Y, et al. BRD4 (bromodomain-containing protein 4) interacts with GATA4 (GATA binding protein 4) to govern mitochondrial homeostasis in adult cardiomyocytes. Circulation. 2020;142(24):2338-55. https://doi.org/10.1161/CIRCULATIONAHA.120.047753.

255. Matsushima S, Sadoshima J. The role of sirtuins in cardiac disease. Am J Physiol Heart Circ Physiol. 2015;309(9):H1375-89. https://doi.org/10.1152/a jpheart.00053.2015.

256. Chong JJ, Yang X, Don CW, Minami E, Liu YW, Weyers JJ, et al. Human embryonic-stem-cell-derived cardiomyocytes regenerate non-human primate hearts. Nature. 2014;510(7504):273-7. https://doi.org/10.1038/na ture13233.

257. Liu YW, Chen B, Yang X, Fugate JA, Kalucki FA, Futakuchi-Tsuchida A, et al. Human embryonic stem cell-derived cardiomyocytes restore function in infarcted hearts of non-human primates. Nat Biotechnol. 2018;36(7):597-605. https://doi.org/10.1038/nbt.4162.

258. Romagnuolo R, Masoudpour H, Porta-Sanchez A, Qiang B, Barry J, Laskary A, et al. Human embryonic stem cell-derived cardiomyocytes regenerate the infarcted pig heart but induce ventricular tachyarrhythmias. Stem Cell Reports. 2019;12(5):967-81. https://doi.org/10.1016/j.stemcr.2019.04.005.
259. Chan YC, Siu CW, Lau YM, Lau CP, Li RA, Tse HF. Synergistic effects of inward rectifier (I) and pacemaker (I) currents on the induction of bioengineered cardiac automaticity. J Cardiovasc Electrophysiol. 2009;20(9): 1048-54. https://doi.org/10.1111/j.1540-8167.2009.01475.x.

260. Saito T, Uchiumi T, Yagi M, Amamoto R, Setoyama D, Matsushima Y, et al. Cardiomyocyte-specific loss of mitochondrial p32/C1qbp causes cardiomyopathy and activates stress responses. Cardiovasc Res. 2017; 113(10):1173-85. https://doi.org/10.1093/cvr/cvx095.

261. Samal E, Evangelista M, Galang G, Srivastava D, Zhao Y, Vedantham V. Premature MicroRNA-1 expression causes hypoplasia of the cardiac ventricular conduction system. Front Physiol. 2019;10:235. https://doi.org/1 0.3389/fphys.2019.00235

262. O'Rourke B, Ramza BM, Marban E. Oscillations of membrane current and excitability driven by metabolic oscillations in heart cells. Science. 1994; 265(5174):962-6. https://doi.org/10.1126/science.8052856.

263. Romashko DN, Marban E, O'Rourke B. Subcellular metabolic transients and mitochondrial redox waves in heart cells. Proc Natl Acad Sci U S A. 1998; 95(4):1618-23. https://doi.org/10.1073/pnas.95.4.1618.

264. Gu JM, Grijalva SI, Fernandez N, Kim E, Foster DB, Cho HC. Induced cardiac pacemaker cells survive metabolic stress owing to their low metabolic demand. Exp Mol Med. 2019;51(9):1-12. https://doi.org/10.1038/s12276-0190303-6.

265. Gordan R, Fefelova N, Gwathmey JK, Xie LH. Involvement of mitochondrial permeability transition pore (MPTP) in cardiac arrhythmias: evidence from cyclophilin D knockout mice. Cell Calcium. 2016;60(6):363-72. https://doi. org/10.1016/j.ceca.2016.09.001.

266. Miklas JW, Clark E, Levy S, Detraux D, Leonard A, Beussman K, et al. TFPa/ $\mathrm{HADHA}$ is required for fatty acid beta-oxidation and cardiolipin re-modeling in human cardiomyocytes. Nat Commun. 2019;10(1):4671. https://doi.org/1 0.1038/s41467-019-12482-1.

267. Zhou L, Cortassa S, Wei AC, Aon MA, Winslow RL, O'Rourke B. Modeling cardiac action potential shortening driven by oxidative stress-induced mitochondrial oscillations in guinea pig cardiomyocytes. Biophys J. 2009; 97(7):1843-52. https://doi.org/10.1016/j.bpj.2009.07.029.

268. Xia Y, Buja LM, Scarpulla RC, McMillin JB. Electrical stimulation of neonatal cardiomyocytes results in the sequential activation of nuclear genes governing mitochondrial proliferation and differentiation. Proc Natl Acad Sci U S A. 1997;94(21):11399-404. https://doi.org/10.1073/pnas.94.21.11399.

269. Liu S, Liu F, Schneider AE, St Amand T, Epstein JA, Gutstein DE. Distinct cardiac malformations caused by absence of connexin 43 in the neural crest and in the non-crest neural tube. Development. 2006;133(10):2063-73. https://doi.org/10.1242/dev.02374.

270. Eckardt D, Kirchhoff S, Kim JS, Degen J, Theis M, Ott T, et al. Cardiomyocyterestricted deletion of connexin43 during mouse development. J Mol Cell Cardiol. 2006:41(6):963-71. https://doi.org/10.1016/j.yjmcc.2006.07.017.

271. Reaume AG, de Sousa PA, Kulkarni S, Langille BL, Zhu D, Davies TC, et al. Cardiac malformation in neonatal mice lacking connexin43. Science. 1995; 267(5205):1831-4. https://doi.org/10.1126/science.7892609.

272. Vaidya D, Tamaddon HS, Lo CW, Taffet SM, Delmar M, Morley GE, et al. Null mutation of connexin43 causes slow propagation of ventricular activation in the late stages of mouse embryonic development. Circ Res. 2001;88(11): 1196-202. https://doi.org/10.1161/hh1101.091107.

273. Gutstein DE, Morley GE, Tamaddon H, Vaidya D, Schneider MD, Chen J, et al. Conduction slowing and sudden arhythmic death in mice with cardiac-restricted inactivation of connexin43. Circ Res. 2001;88(3):333-9. https//doi.org/10.1161/01.res.88.3.333.

274. Poelzing S, Rosenbaum DS. Altered connexin43 expression produces arrhythmia substrate in heart failure. Am J Physiol Heart Circ Physiol. 2004; 287(4):H1762-70. https://doi.org/10.1152/ajpheart.00346.2004.

275. Greener ID, Sasano T, Wan X, Igarashi T, Strom M, Rosenbaum DS, et al. Connexin43 gene transfer reduces ventricular tachycardia susceptibility after myocardial infarction. J Am Coll Cardiol. 2012;60(12):1103-10. https://doi. org/10.1016/j.jacc.2012.04.042.

276. Smyth JW, Shaw RM. Autoregulation of connexin43 gap junction formation by internally translated isoforms. Cell Rep. 2013;5(3):611-8. https://doi.org/1 0.1016/j.celrep.2013.10.009.

277. Xiao S, Shimura D, Baum R, Hernandez DM, Agvanian S, Nagaoka Y, et al. Auxiliary trafficking subunit GJA1-20k protects connexin-43 from degradation and limits ventricular arrhythmias. J Clin Invest. 2020;130(9): 4858-70. https://doi.org/10.1172/JCl134682.

278. Basheer WA, Fu Y, Shimura D, Xiao S, Agvanian S, Hernandez DM, et al. Stress response protein GJA1-20k promotes mitochondrial biogenesis, 
metabolic quiescence, and cardioprotection against ischemia/reperfusion injury. JCl Insight. 2018;3(20) https://doi.org/10.1172/jci.insight.121900.

279. Sottas V, Wahl CM, Trache MC, Bartolf-Kopp M, Cambridge S, Hecker M, et al. Improving electrical properties of iPSC-cardiomyocytes by enhancing Cx43 expression. J Mol Cell Cardiol. 2018;120:31-41. https://doi.org/10.1016/ j.yjmcc.2018.05.010.

280. Li X, Yu L, Gao J, Bi X, Zhang J, Xu S, et al. Apelin ameliorates high glucoseinduced downregulation of connexin 43 via AMPK-dependent pathway in neonatal rat cardiomyocytes. Aging Dis. 2018;9(1):66-76. https://doi.org/1 0.14336/AD.2017.0426.

281. Fu YL, Tao L, Peng FH, Zheng NZ, Lin Q, Cai SY, et al. GJA1-20k attenuates Ang II-induced pathological cardiac hypertrophy by regulating gap junction formation and mitochondrial function. Acta Pharmacol Sin. 2020; https://doi. org/10.1038/s41401-020-0459-6.

282. Ferko M, Andelova N, Szeiffova Bacova B, Jasova M. Myocardial adaptation in pseudohypoxia: signaling and regulation of MPTP via mitochondria connexin 43 and cardiolipin. Cells. 2019;8(11) https://doi.org/10.3390/ cells8111449.

283. Fu Y, Zhang SS, Xiao S, Basheer WA, Baum R, Epifantseva I, et al. CX43 Isoform GJA1-20k promotes microtubule dependent mitochondrial transport. Front Physiol. 2017;8:905. https://doi.org/10.3389/fphys.2017. 00905.

284. Givvimani S, Pushpakumar S, Veeranki S, Tyagi SC. Dysregulation of Mfn2 and Drp-1 proteins in heart failure. Can J Physiol Pharmacol. 2014;92(7):58391. https://doi.org/10.1139/cjpp-2014-0060.

285. Statuto M, Bianchi C, Perego R, Del Monte U. Drop of connexin 43 in replicative senescence of human fibroblasts HEL-299 as a possible biomarker of senescence. Exp Gerontol. 2002;37(8-9):1113-20. https://doi. org/10.1016/s0531-5565(02)00089-x.

286. Zhang X, Chen X, Wu D, Liu W, Wang J, Feng Z, et al. Downregulation of connexin 43 expression by high glucose induces senescence in glomerular mesangial cells. J Am Soc Nephrol. 2006;17(6):1532-42. https://doi.org/10.1 681/ASN.2005070776.

287. Taniguchi Ishikawa E, Gonzalez-Nieto D, Ghiaur G, Dunn SK, Ficker AM, Murali B, et al. Connexin-43 prevents hematopoietic stem cell senescence through transfer of reactive oxygen species to bone marrow stromal cells. Proc Natl Acad Sci U S A. 2012;109(23):9071-6. https://doi.org/10.1073/pna S.1120358109.

288. Varela-Eirin M, Varela-Vazquez A, Guitian-Caamano A, Paino CL, Mato V, Largo R, et al. Targeting of chondrocyte plasticity via connexin43 modulation attenuates cellular senescence and fosters a pro-regenerative environment in osteoarthritis. Cell Death Dis. 2018;9(12):1166. https://doi. org/10.1038/s41419-018-1225-2.

289. Dhamoon AS, Jalife J. The inward rectifier current (IK1) controls cardiac excitability and is involved in arrhythmogenesis. Heart Rhythm. 2005;2(3): 316-24. https://doi.org/10.1016/j.hrthm.2004.11.012

290. Woo J, Kim HJ, Nam YR, Kim YK, Lee EJ, Choi I, et al. Mitochondrial dysfunction reduces the activity of KIR2.1 K(+) channel in myoblasts via impaired oxidative phosphorylation. Korean J Physiol Pharmacol. 2018;22(6): 697-703. https://doi.org/10.4196/kjpp.2018.22.6.697.

291. Alesutan I, Munoz C, Sopjani M, Dermaku-Sopjani M, Michael D, Fraser S, et al. Inhibition of Kir2.1 (KCNJ2) by the AMP-activated protein kinase. Biochem Biophys Res Commun. 2011;408(4):505-10. https://doi.org/10.1016/ j.bbrc.2011.04.015.

292. Sarikhani M, Garbern JC, Ma S, Sereda R, Conde J, Krahenbuhl G, et al. Sustained activation of AMPK enhances differentiation of human IPSCderived cardiomyocytes via sirtuin activation. Stem Cell Reports. 2020;15(2): 498-514. https://doi.org/10.1016/j.stemcr.2020.06.012.

293. Hsieh LS, Wen JH, Nguyen LH, Zhang L, Getz SA, Torres-Reveron J, et al. Ectopic HCN4 expression drives mTOR-dependent epilepsy in mice. Sci Transl Med. 2020;12(570) https://doi.org/10.1126/scitransImed.abc1492.

\section{Publisher's Note}

Springer Nature remains neutral with regard to jurisdictional claims in published maps and institutional affiliations. 